\title{
HISTORICAL INCIDENCE OF MODIFIED MERCALLI INTENSITY IN NEW ZEALAND AND COMPARISONS WITH HAZARD MODELS
}

\author{
D. J. Dowrick ${ }^{1,2}$ and W. J. Cousins ${ }^{1,3}$
}

\begin{abstract}
SUMMARY
The historical incidence of Modified Mercalli intensity produced by earthquakes of magnitude $\mathrm{M}_{\mathrm{W}} \geq$ 5.25 and depth $\leq 100 \mathrm{~km}$ has been determined for 47 locations in New Zealand for the period 1840-1997 inclusive. Maps for the return periods of intensities MM4 - MM7 were prepared. The effects of the highly attenuating Taupo Volcanic Zone (TVZ) were shown to be important for hazard both in the zone and in areas to the north-west of it. The rate of occurrence of the higher intensities was found to be about 2.5 times greater in the first century of the study period than in the last 50 years. The historical seismic hazard rates for intensities MM5 and MM6 averaged across the country were found to be approximately half those of the now obsolete Smith \& Berryman seismic hazard model, and $70 \%$ of those of the more recent Stirling et al model.
\end{abstract}

\section{INTRODUCTION}

The historical seismicity of a region provides an essential cornerstone to and a most tangible reality check on its seismic hazard models. In order to have the greatest time record of historical observations of earthquake shaking it is necessary to work in terms of intensity. This allows us to go back as early as about 1840 in most parts of New Zealand, currently giving a database of up to 158 years duration, compared to a maximum of about 35 years for strong-motion accelerograph records. However the completeness era for intensities of MM4 and above and for magnitudes greater than 5.25 is restricted to the period 1943 to the present.

In the past the historical incidence of intensity has been examined for some individual locations, such as for Auckland [5, 13] and Christchurch [11, 25]. A fairly comprehensive country-wide survey was published by Hayes [16] in 1936, in which the incidence of intensity was counted for 16 locations in the North Island and nine in the South Island. However Hayes' data suffers badly in quality because the intensities were given in terms of the very poor Rossi-Forel scale which was in use in New Zealand up to 1944.

In the present study the intensities used are mostly in terms of the Modified Mercalli scale as defined over the years for New Zealand [7, 14, 21]. In order to examine the historical shaking hazard across the whole country, the incidence of intensity has been estimated for 47 localities distributed from Whangarei to Invercargill, 23 and 24 in the North and South Islands respectively (Figure 1).

It was decided that the preferred intensities to be examined in the study would be isoseismals (see below) rather than the actual observations. This was done because a prime use of the results of the study is to compare its results with those obtained from estimates of probabilistic hazard for any part of the country, and the New Zealand attenuation functions for intensity are in terms of the spatial distribution of isoseismals [10].

\section{THE DATA}

The earthquakes considered in this study comprised events of engineering hazard interest, i.e. restricted to those of magnitude 5.25 or more that could have been felt at any of the 47 chosen locations at an intensity of MM4 or greater in the time period 1840-1997 inclusive. Because of incompleteness of the data, the results are based only on intensities of MM4 or greater produced (or estimated to have been produced) by earthquakes of magnitude 6.5 and greater from 1840 to 1942 , and magnitudes 5.25 and greater since 1943. Such data were available for earthquakes with focal depths ranging down to $400 \mathrm{~km}$, but the results given here consider data restricted to depths down to $100 \mathrm{~km}$. The minimum magnitude and maximum depth were adopted to be the same as those currently considered in modelling seismic hazard in New Zealand [26]. Depths throughout are assumed to be the centroid depth, $h_{c}$, as used in attenuation modelling [10].

The events used in the study were a subset of those used in the new seismic hazard model for New Zealand [26], which in turn were a subset of those in the New Zealand earthquake catalogue [22, e.g.17]. The New Zealand earthquake catalogue contains magnitudes, locations and times for all New Zealand earthquakes since 1840 that have been either recorded or sufficiently well documented macroseismically. For events prior to about 1940 the data are derived partly from felt reports and hence tend to be mostly for the larger events and often not well constrained. During 1943 a network of seismographs was established throughout New Zealand with the result that the quality of the seismic data improved greatly over that of the earlier years and smaller earthquakes were able to be included. Major upgrades to the network took place in 1964 and 1990.

\footnotetext{
${ }^{1}$ Institute of Geological \& Nuclear Sciences, Lower Hutt

${ }^{2}$ Fellow

${ }^{3}$ Member
} 


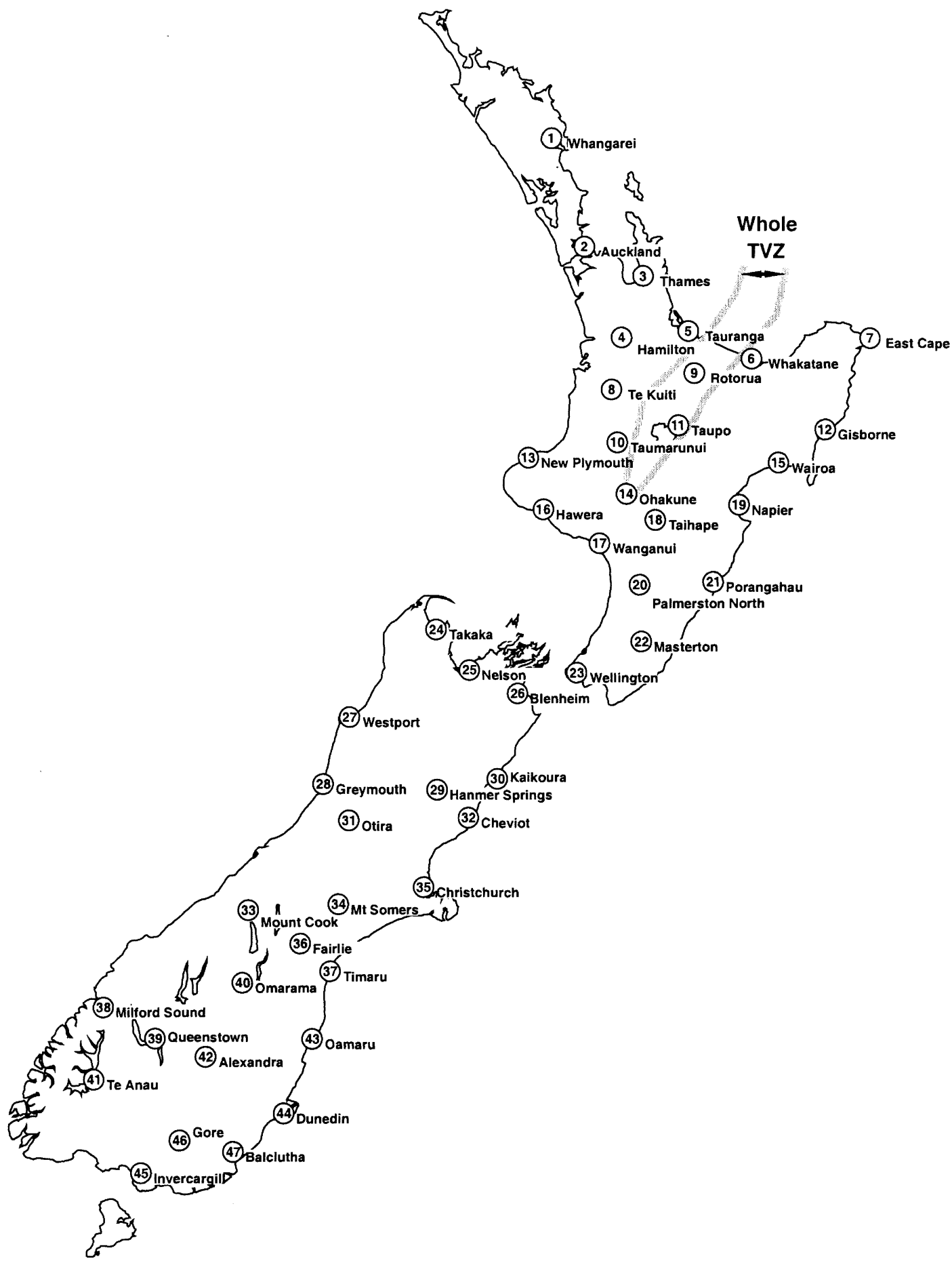

Figure 1: Map of New Zealand showing the 47 locations studied.

Currently the New Zealand catalogue contains more than 100,000 entries for earthquakes of magnitude 2.5 and greater. It is believed to have captured all earthquakes with magnitudes $\geq 6.5$ since $1840, \geq 5$ since 1943 , and $\geq 4$ since 1964. There are about 20,400 events of local magnitude $\left(\mathrm{M}_{\mathrm{L}}\right)$ 4 and greater.

The catalogue used in the new seismic hazard model was derived from the New Zealand catalogue by "declustering", which is a process in which a mainshock plus its foreshocks and aftershocks (if any) were replaced by a single equivalent event that had the same overall energy release $[18,19]$ Declustering had the effect of reducing the number of earthquakes in the catalogue to about two thirds the original number. The declustered catalogue contained 12,149 events with local magnitudes $\geq 4.0$, and of those 442 had moment magnitudes $\geq 5.25$. Further information on the numbers is given in Table 1. 
Table 1: $\quad$ Some statistics for the events in the declustered earthquake catalogue. In the original declustered catalogue the measure of magnitude was the local magnitude $\left(\mathrm{M}_{\mathrm{L}}\right)$. For the intensity study we have used the moment magnitude $\left(M_{W}\right)$ with values obtained as outlined in Section 2 . The events used in our study are marked with asterisks, i.e. those 408 with moment magnitudes of 5.25 and greater at depths of $100 \mathrm{~km}$ or less.

\begin{tabular}{|c|c|c|c|c|c|}
\hline $\mathbf{M}_{\mathbf{L}}$ & $\begin{array}{c}\text { Depth } \\
(\mathbf{k m})\end{array}$ & Number & $\mathbf{M}_{\mathbf{W}}$ & $\begin{array}{c}\text { Depth } \\
\text { (km) }\end{array}$ & Number \\
\hline \multirow{4}{*}{$4.0-5.2$} & $0-70$ & 4649 & \multirow{4}{*}{$5.00-5.24$} & $0-70$ & 356 \\
\hline & $71-100$ & 1279 & & $71-100$ & 32 \\
\hline & $101-400$ & 5594 & & $101-260$ & 39 \\
\hline & all & 11522 & & all & 427 \\
\hline \multirow{4}{*}{$5.3-8.1$} & $0-70$ & 295 & \multirow{4}{*}{$5.25-8.20$} & $0-70$ & $377^{*}$ \\
\hline & $71-100$ & 52 & & $71-100$ & $31^{*}$ \\
\hline & $101-375$ & 280 & & $101-375$ & 34 \\
\hline & all & 627 & & all & 442 \\
\hline
\end{tabular}

In both the New Zealand earthquake catalogue and the declustered version most of the magnitudes are local magnitudes. The exceptions are the magnitudes for some of the pre-1940 events for which macroseismic magnitudes are listed. Because the attenuation model for $\mathrm{MM}$ intensity is based on moment magnitude, we obtained $\mathrm{M}_{\mathrm{W}}$ values as follows:

- The list compiled by Dowrick \& Rhoades [9],

- $\mathrm{M}_{\mathrm{W}}$ derived from $\mathrm{M}_{\mathrm{L}}$ using a relationship between them [9],

- Moments determined at Harvard [12] for post-1993 events (i.e. post ref. [9]), and

- Macroseismic magnitudes.

Declustering eliminates many events that have been felt. Of the 781 felt events that have moment magnitudes of 5.25 and greater, only 325 are found in the declustered catalogue.

The locations and magnitudes of the events considered in this study are plotted on maps as follows:

- $\quad$ events with $h_{c} \leq 70 \mathrm{~km}$ (Figure 2)

- $\quad$ events with $70<h_{c} \leq 100 \mathrm{~km}$ (Figure 3).

Intensity data were derived from three sources, which were:

i. an isoseismal map, I(map),

ii. a local observation of intensity, I(obs), and

iii. an intensity calculated using event magnitude and location with an attenuation model for intensity, I(calc).
The preferred sources of the intensity data were isoseismal maps (item (i) above), of which 162 were available plotted in Modified Mercalli intensity terms. The isoseismal maps used came from various sources, i.e. the atlas of isoseismal maps produced by Downes [2], maps produced by Dowrick for his attenuation study [10], various maps by Dowrick, Downes and others $[3,4,6,8,25]$ and a few prepared specially for the purposes of this study. An example of an isoseismal map is that for one of the largest events in the data set, the $\mathrm{M}_{\mathrm{W}} 7.7$ Murchison (Buller) earthquake of 1929 [6], as shown in Figure 4. The intensity assigned to each location is that of the intensity zone within which the given locality falls. An intensity zone is defined such that the intensity 5 zone, for example, is the area between the MM5 and MM6 isoseismals. In the case of the event shown in Figure 4 most, i.e. 39 , of the 47 localities in the study experienced intensity MM4 or greater.

For many of the events where no isoseismal map was available, local observations of intensity were found in the computer database compiled for events from 1943 onwards by the New Zealand Seismological Observatory. This information is held in a computer file that can be interrogated electronically. In addition, for a few of the pre-1943 events, some general indications of intensity noted by Eiby [15] were the only readily available data. For some of the earthquakes further intensity data were sought from newspaper reports as part of this study. 
1840-1942, Mw 7.0+

$1840-1942,6.0-6.9$

$1840-1942,5.25-5.9$

1943-1997, Mw 7.0+

$1943-1997,6.0-6.9$

○ $1943-1997,5.25-5.9$
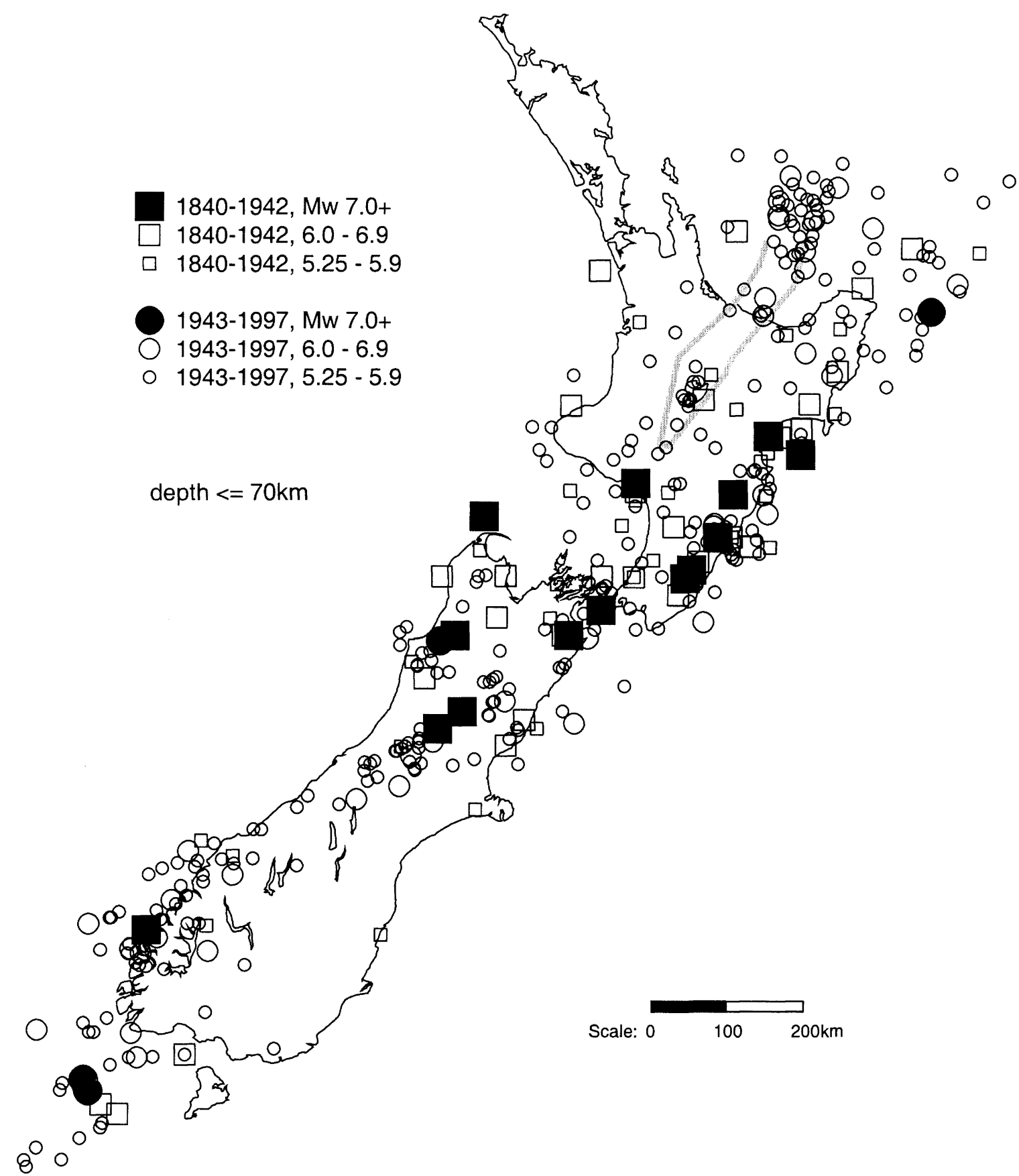

Figure 2: Epicentres of earthquakes of $M_{W} \geq 5.25$ and depth range $\leq 70 \mathrm{~km}$. Note the mostly favourable locations of the large events $\left(M_{W} \geq 7\right)$ since 1942 , i.e. away from the 47 study locations.

The computer database contains felt reports from approximately 8350 events that occurred in the period 1 January 1943 to 31 December 1997. Of those events, 781 have estimated moment magnitudes of 5.25 and above.

There were some deficiencies with some of the 'felt' data however. The deficiencies, and actions taken to ameliorate them, were as follows:

- $\quad$ varying intensity scales, i.e. most of the original felt reports for events prior to 1944 were in terms of the Rossi-Forel scale and have since been converted to the MM scale in a way that has not been documented [corrective action: reassessments of intensity were carried out where discrepancies were noted and sufficient basic information was available],

- multiple readings at one location [the largest reading was used],

- uncertain values, e.g. MM3-4 [the first (smaller) value was used],

- non-standard readings, e.g. "Force 5" [was equated with MM5], and

- descriptions, e.g. "jolt", "tremor" [the following translations were adopted: 
MM0 for "not felt",

MM1 for "v. slight",

MM2 for "light", "small", "slight”, "tremor", "gentle", "mild", "?",

MM3 for "felt", "short", "steady", "long", "medium", "prolonged", "shake", "roll", "sway",

MM4 for "jolt", "loud", "moderate", "sharp", "big”, "heavy", "strong", and
MM5 for "damage”, "severe”, "very heavy”.]

The third avenue available for assigning an intensity at any given location was to estimate it from the magnitude $\mathrm{M}_{\mathrm{W}}$ and depth of the event, and the distance from the event to the site, using the attenuation expression for MM intensity from Dowrick \& Rhoades [10] as discussed in Section 3.

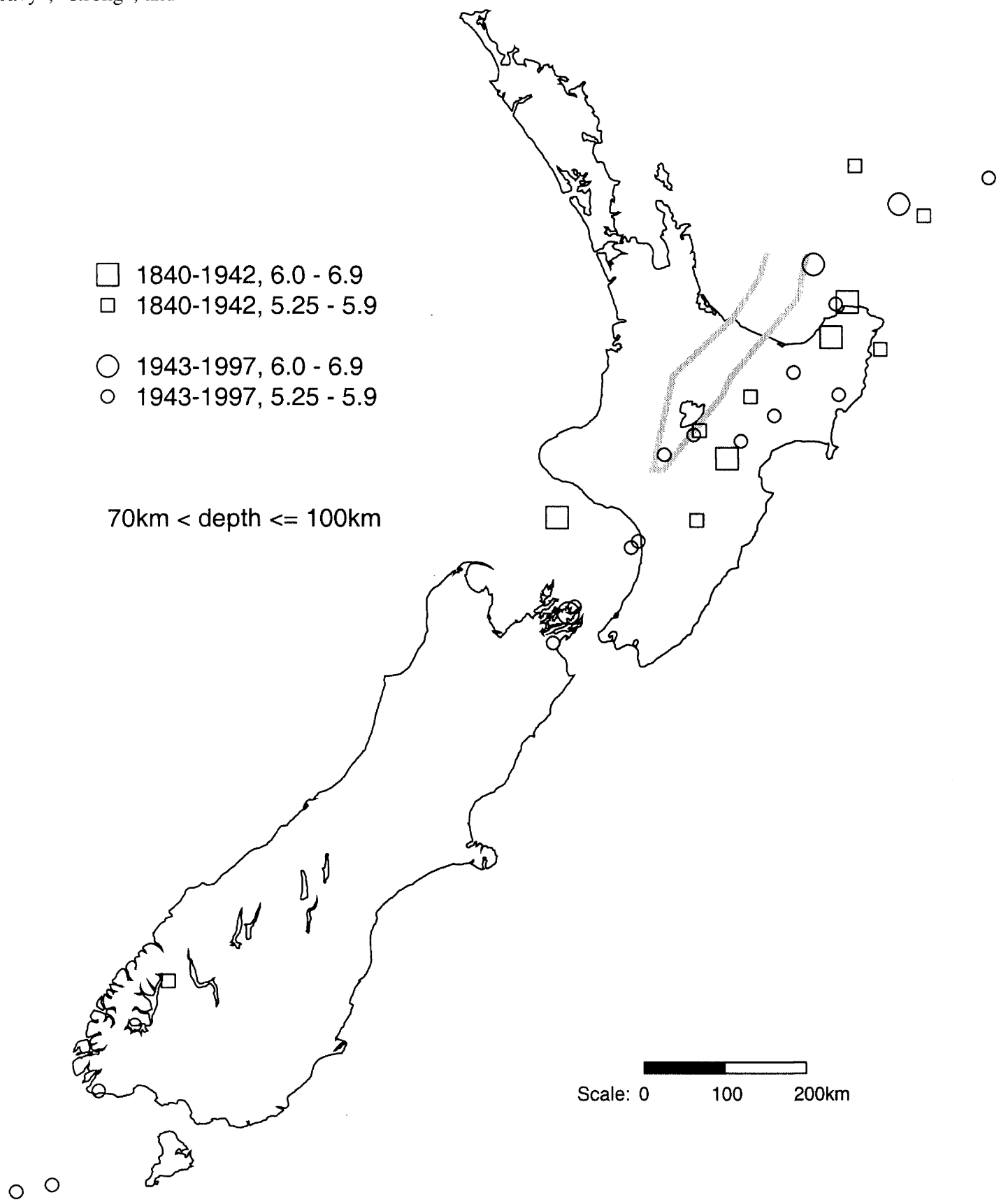

Figure 3: Epicentres of earthquakes of $M_{W} \geq 5.25$ and depth range $70<h \leq 100 \mathrm{~km}$.

The agreement between the intensity values derived from the three sources is illustrated in Figure 5, (a) for cases where both I(map) and I(obs) values are available, and (b) for cases where I(map) and I(calc) values are available. Note that in both cases the comparisons are restricted to intensity values of MM4 and greater because the data are incomplete for the smaller values.

It can be seen that $96 \%$ of the $\mathrm{I}(\mathrm{obs})$ values are within 1 intensity unit of the corresponding mapped values, as are $98 \%$ of the $\mathrm{I}$ (calc) values. The average value of $\mathrm{I}(\mathrm{map})-\mathrm{I}(\mathrm{obs})$ (the mean residual) is -0.14 , i.e. I(map) is on average smaller 
than $\mathrm{I}(\mathrm{obs})$ by 0.14 , and that for $\mathrm{I}(\mathrm{map})-\mathrm{I}(\mathrm{calc})$ is -0.06 .

Data from our most preferred source, I(map), comprise $57 \%$ of the total and data from the second most preferred source, I(obs), make up $17 \%$. Most, $80 \%$, of the higher intensity occurrences, i.e. MM7 and above, are I(map) data. We are reliant on the least preferred value of intensity, I(calc), for $26 \%$ of the data. These cases arise mostly from early illdefined events, like the 1843 Wanganui earthquake of
$M \approx 7.5$, or low magnitude events. It should be noted that the mean residual of I(map)-I(calc) is only -0.06 . Thus, as the magnitudes and locations of events with isoseismal maps are generally well determined, the attenuation model can be regarded as very reliable. This means that for events where only $\mathrm{I}(\mathrm{calc})$ is available, the uncertainties in $\mathrm{I}(\mathrm{calc})$ data will arise mainly from uncertainties in the magnitudes and locations of the earthquakes concerned. Most of the $\mathrm{I}$ (calc) data, 99\%, comprises intensities of MM6 and smaller.

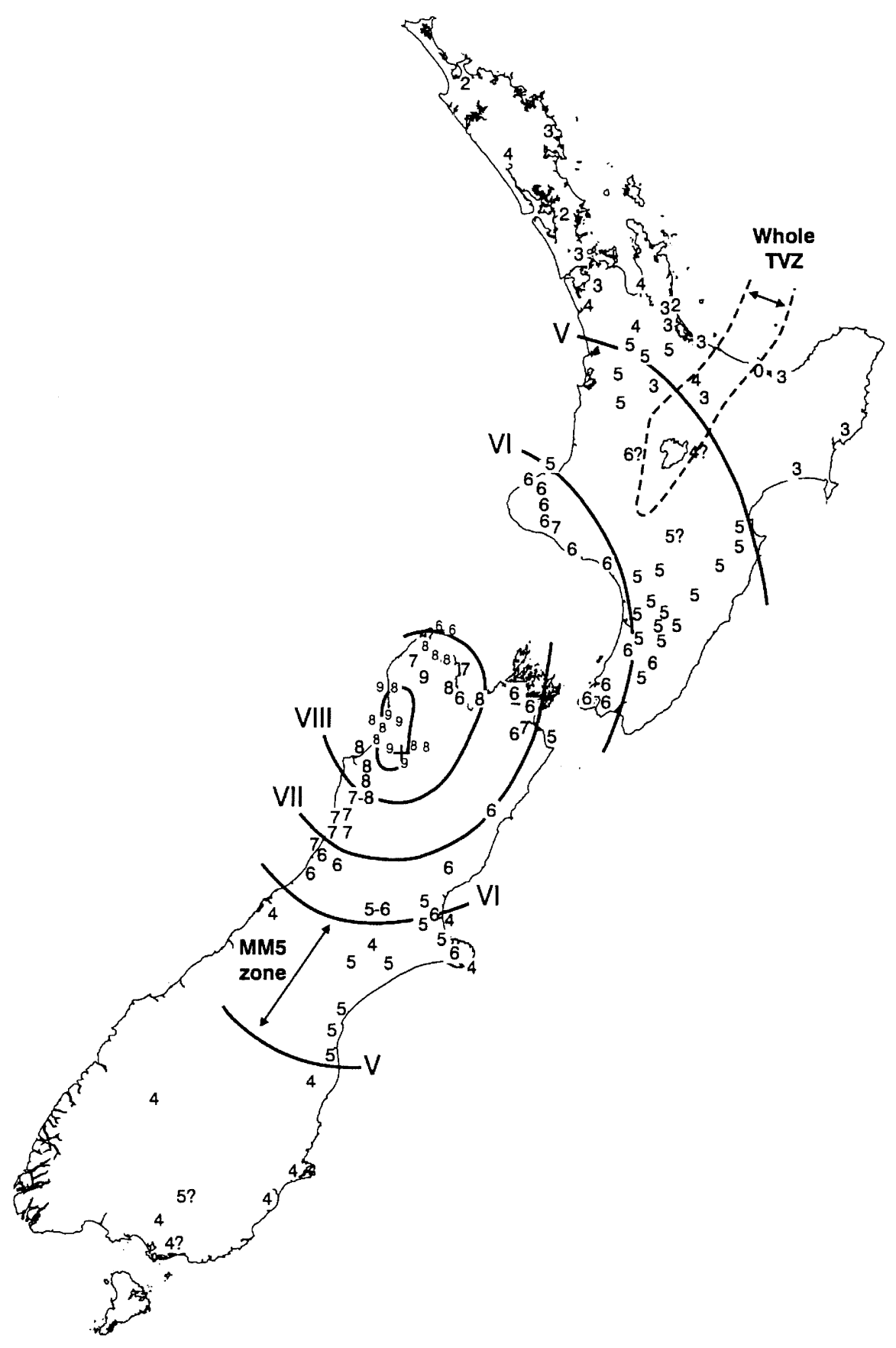

Figure 4: Map showing a typical example of Modified Mercalli intensity isoseismals, the $M_{W} 7.7$ Murchison (Buller) earthquake of 1929 [2, 6]. Although no MMIV contour was drawn by the author of the map we can confidently place the southern part of the South Island within an MMIV zone. The situation in the north east part of the North Island is confused and so there we are reduced to using spot readings for the nine study locations outside of the MMV contour. 

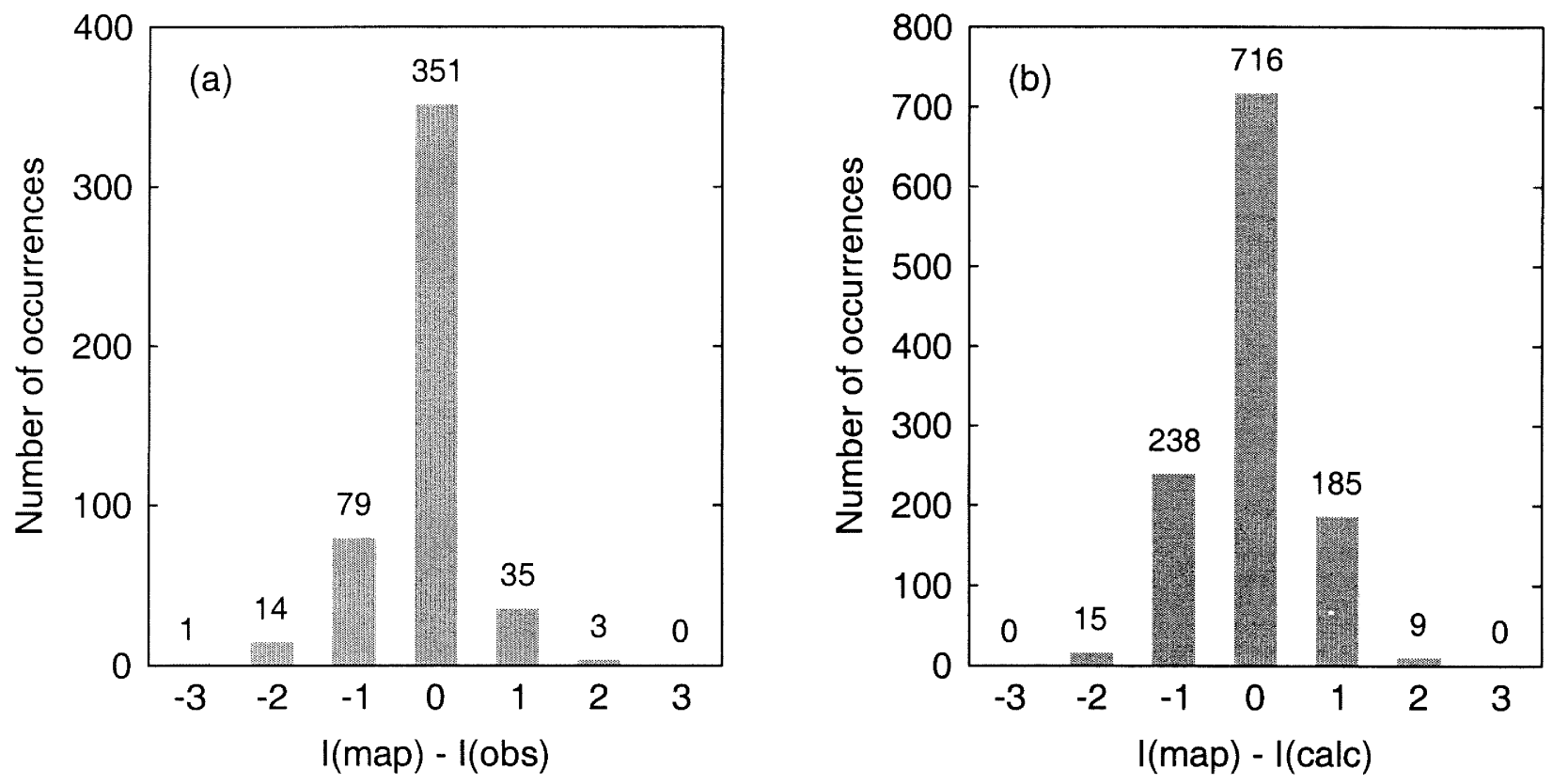

Figure 5: Distributions of residuals, (a) for I(map) - I(obs) and (b) for I(map) - I(calc).

\section{THE CALCULATIONS}

\subsection{Derivation of $I($ calc $)$}

To estimate the intensity $\mathrm{I}$ (calc) at a given location using attenuation models, the following simplified approach was adopted. Regardless of the locations of the event and the site being considered, all events were initially treated as being the same from an attenuation point of view, i.e. the "Main Seismic Region" model of Dowrick \& Rhoades [10] was used. Mean intensities were calculated as real numbers that were then truncated to give integer zone intensities. For those events where at least $20 \mathrm{~km}$ of the travel path was through the highly attenuating Taupo Volcanic Zone $[1,10,24]$ (i.e. the "whole TVZ" of Figure 1), I(calc) was reduced by 1 to 2 units of intensity (before being truncated). This procedure was called volcanic "screening", and was implemented by a mapping technique. An example of one of four screening maps used is shown in Figure 6. It illustrates the screening of events located within and north-west of the TVZ from observation sites located to the south-east. Direct paths from events to sites were assumed, and effective screening was assumed to require a minimum of $20 \mathrm{~km}$ of path length within the TVZ. (The minimum TVZ path length of $20 \mathrm{~km}$ is the reason for the offset of the SW-NE boundary line (Figure 6) from the eastern boundary of the TVZ.) For reasons of practicality the screened events were grouped into 4 sectors, and the events in each sector were "tagged" so as to indicate which sites they were screened from.

The amount by which MMI should be reduced for a TVZ path was determined by comparing all available pairs of $\mathrm{I}(\mathrm{calc})$ and I(map) or I(obs) values for each location for the "tagged" events. For crustal events (i.e. those with $h_{c} \leq 70$ $\mathrm{km})$, the apparent reduction factors were found to be as follows:

- Whangarei and Auckland:

$2.0 \quad \mathrm{MM}$ units,

- Thames:

$1.5 \mathrm{MM}$

\section{- Rotorua:}

- all other North Island locations: 1.0 MM unit.

The above "TVZ" procedure is very much ad hoc, but is necessitated by the lack of an MMI attenuation model that can accommodate paths that are only partly within the TVZ. No great reliance should be placed on the apparent reduction factors for Whangarei, Auckland and Thames because they are based on few data.

For deep events located beneath and north-west of the TVZ, we assumed that the travel paths were up the descending tectonic slab to a region east of the TVZ and then horizontally through the TVZ to sites located north-west of the TVZ. A TVZ reduction factor of $1.0 \mathrm{MM}$ unit was then applied to the following locations, Whangarei, Auckland, Thames, Hamilton, Tauranga, Te Kuiti, Taumarunui, New Plymouth and Hawera.

A further simplification in the attenuation modelling was to assume that the isoseismals were circular, which in some cases, results in the intensity being over or under-estimated by one unit of intensity. This is more likely to occur in the near field of larger shallow earthquakes where ellipticity is strongest, but as nearly all such events had isoseismal maps or local observations of intensity (the preferred sources of intensity data), this approximation had only a small impact on the results.

The final simplification in the attenuation modelling concerned the deep events $\left(h_{c}>70 \mathrm{~km}\right)$ in the dipping slab under the North Island. We investigated the possibility of applying a "deep event" reduction factor for those deep events where the path from source to observation site was not direct but instead was up the descending slab and then horizontally through the crust. This was found to be counterproductive and was not retained in the model at this stage. unit, 


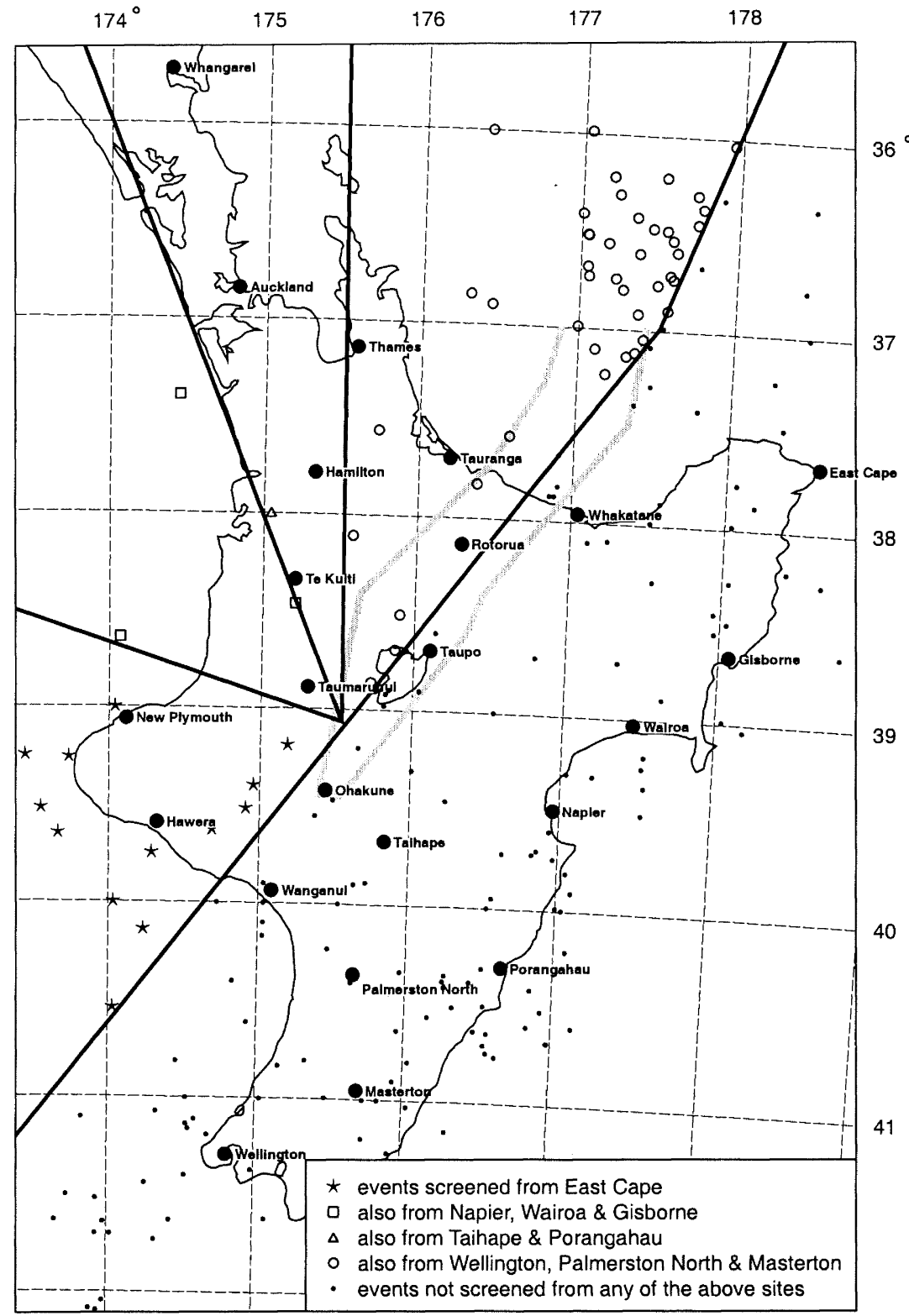

Figure 6: Example of map used in calculating intensities affected by volcanic travel paths. It illustrates the screening of events located within and north-west of the TVZ from observation sites located to the south-east. Direct paths from events to sites were assumed, and effective screening was assumed to require a minimum of $20 \mathrm{~km}$ of path length within the TVZ. (The minimum TVZ path length of $20 \mathrm{~km}$ is the reason for the offset of the $S W-N E$ boundary line (Figure 5) from the eastern boundary of the TVZ.) Note that observation sites Whakatane, Rotorua, Taupo and Ohakune are dealt with separately.

3.2

\section{Occurrence of intensity}

As discussed above, intensities at each location were found for all events in the catalogue by one or more of three methods. When more than one estimate was available the one selected was the value found by the most preferred method, with the (decreasing) order of preference being mapped (I(map)), local observation (I(obs)), or estimate from attenuation model (I(calc)). The selected intensity values were then counted by intensity level $\geq$ MM4 for each location.
As an example of the calculations, consider the case of Rotorua, the data and results for which are presented in Table 2. Of the 34 events listed, 23 have I(map) values and a further seven have I(obs), leaving only four where the only estimate of intensity is I(calc). These isolated I(calc) values are all only MM4. The mean difference between I(calc) and $\mathrm{I}$ (map) or I(obs) is -0.1 for this location (I(calc) being the lower). Similar results for all locations are summarised in Tables 3 and 4.

Up to this point, all counts of occurrences have been for the 
entire 158-year period from 1840 to 1997 , regardless of the degree of completeness of the historical record. Incompleteness of the pre-1943 historical record is illustrated in Table 2, where it is seen that 14 events are listed for the 103 year period 1840-1942 compared with 20 events for the 55 years period 1943-1997. As a way of quantifying the apparent variation in occurrence rates, the counts of intensity levels (obtained from the combination of I(map), I(obs) and $\mathrm{I}(\mathrm{calc})$ ) were repeated for two time periods, (i) 1840 to 1942 inclusive ("pre-1943", duration 103 years) and (ii) 1943 to 1977 inclusive ("post-(1 January)1943", duration 55 years). The counts were then converted to apparent rates by dividing by the time period of 103 or 55 years as appropriate.

Table 2: Shaking intensities noted at Rotorua, over the period 1840 to 1997 inclusive, for all earthquakes that have resulted in either calculated ("calc"), mapped ("map") or felt ("obs") intensities of MM4 or more. "Epicd" is the epicentral distance and " $\mathrm{nr}$ " indicates that there was no felt report from the site concerned. Note that the length of path within the TVZ for all of the events was more than $20 \mathrm{~km}$ and so a TVZ correction factor has been applied to all of the calculated intensities.

\begin{tabular}{|c|c|c|c|c|c|c|c|c|c|}
\hline \multirow{2}{*}{$\begin{array}{c}\text { Earthquake } \\
\text { Date }\end{array}$} & \multirow{2}{*}{$\begin{array}{l}\text { Time } \\
\text { (UT) }\end{array}$} & \multirow[t]{2}{*}{ Lat. } & \multirow[t]{2}{*}{ Long. } & \multirow{2}{*}{$\begin{array}{c}\text { Depth } \\
(\mathbf{k m})\end{array}$} & \multirow[t]{2}{*}{ Mw } & \multirow{2}{*}{$\begin{array}{l}\text { Epicd } \\
(\mathbf{k m})\end{array}$} & \multicolumn{3}{|c|}{ MMI } \\
\hline & & & & & & & I(calc) & I(map) & I(obs) \\
\hline 18430708 & 0000 & 39.90 & 175.00 & 12 & 7.50 & 224 & 4 & - & $\mathrm{nr}$ \\
\hline 18550123 & 0932 & 41.40 & 174.50 & 19 & 8.20 & 392 & 4 & 3 & - \\
\hline 18630222 & 0000 & 40.00 & 176.50 & 12 & 7.50 & 208 & 4 & - & 4 \\
\hline 19141006 & 1916 & 37.50 & 178.30 & 15 & 6.60 & 193 & 3 & 4 & - \\
\hline 19141028 & 0016 & 37.50 & 178.30 & 15 & 6.38 & 193 & 3 & 4 & - \\
\hline 19210628 & 1358 & 39.30 & 176.40 & 80 & 6.58 & 130 & 4 & 4 & - \\
\hline 19310202 & 2246 & 39.30 & 177.00 & 17 & 7.79 & 145 & 5 & 5 & - \\
\hline 19310213 & 0127 & 39.50 & 177.50 & 17 & 7.22 & 186 & 4 & 4 & - \\
\hline 19310921 & 1334 & 37.50 & 178.00 & 75 & 6.23 & 169 & 3 & 5 & - \\
\hline 19320915 & 1355 & 38.90 & 177.60 & 13 & 6.79 & 145 & 4 & 4 & - \\
\hline 19340305 & 1146 & 40.51 & 176.29 & 12 & 7.36 & 264 & 4 & 4 & - \\
\hline 19340315 & 1046 & 39.31 & 177.17 & 40 & 6.42 & 153 & 4 & 3 & - \\
\hline 19401007 & 0126 & 38.60 & 176.70 & 80 & 5.60 & 64 & 4 & - & 3 \\
\hline 19420624 & 1116 & 40.90 & 175.90 & 12 & 7.07 & 309 & 3 & 4 & - \\
\hline 19510423 & 0650 & 37.53 & 177.84 & 80 & 5.99 & 155 & 3 & 4 & - \\
\hline 19510624 & 0441 & 39.46 & 176.20 & 25 & 5.51 & 147 & 3 & 4 & - \\
\hline 19510625 & 1834 & 38.51 & 175.86 & 10 & 5.58 & 54 & 4 & - & $\mathrm{nr}$ \\
\hline 19530114 & 0143 & 37.83 & 176.86 & 15 & 5.55 & 63 & 4 & - & $\mathrm{nr}$ \\
\hline 19561228 & 1424 & 38.30 & 177.50 & 30 & 6.47 & 110 & 4 & 2 & - \\
\hline 19630412 & 0841 & 38.71 & 176.76 & 20 & 5.82 & 77 & 4 & 3 & - \\
\hline 19650615 & 0920 & 37.90 & 177.53 & 50 & 5.62 & 115 & 3 & 4 & - \\
\hline 19720108 & 2133 & 37.57 & 175.69 & 7 & 5.26 & 80 & 3 & 4 & - \\
\hline 19761027 & 2057 & 37.83 & 176.34 & 5 & 5.27 & 35 & 4 & 3 & - \\
\hline 19840308 & 0041 & 38.31 & 177.29 & 80 & 5.91 & 93 & 4 & 5 & - \\
\hline 19850719 & 1433 & 38.72 & 177.30 & 31 & 5.92 & 112 & 3 & 4 & - \\
\hline 19850926 & 0727 & 36.79 & 178.40 & 61 & 6.89 & 242 & 4 & - & 3 \\
\hline 19870302 & 0142 & 37.88 & 176.84 & 6 & 6.53 & 59 & 5 & 5 & - \\
\hline 19900513 & 0423 & 40.35 & 176.23 & 11 & 6.37 & 246 & 2 & 4 & - \\
\hline 19920325 & 1727 & 37.24 & 177.13 & 9 & 5.92 & 126 & 3 & - & 4 \\
\hline 19920621 & 1743 & 37.67 & 176.86 & 4 & 6.26 & 74 & 4 & - & 4 \\
\hline 19930810 & 0946 & 38.55 & 177.92 & 39 & 6.19 & 152 & 4 & 4 & - \\
\hline 19940331 & 1153 & 38.11 & 177.07 & 66 & 5.69 & 71 & 4 & - & $\mathrm{nr}$ \\
\hline 19941215 & 1120 & 37.11 & 177.50 & 78 & 6.31 & 158 & 4 & - & 3 \\
\hline 19950205 & 2251 & 37.73 & 179.35 & 54 & 7.09 & 275 & 4 & - & 3 \\
\hline \multirow{2}{*}{$\begin{array}{l}\text { Summary of } \\
\text { Occurrences }\end{array}$} & \multicolumn{2}{|c|}{$\mathrm{MMI}=4$} & $\mathrm{n}=21$ & & & & & & \\
\hline & \multicolumn{2}{|c|}{$\mathrm{MMI}=5$} & $n=4$ & & & & & & \\
\hline
\end{tabular}

The results for each location are summarised in Table 5 as ratios of the "pre-1943"/"post-1943" rates. As expected the rates of occurrence of MM4 and MM5 are much higher "post-1943" than "pre-1943". There is, however, an approximate equality for MM6, while for MM7 to MM10 the rates are higher for the "pre-1943" period. Thus there appear to be two opposing factors: i.e. a probable incompleteness of the intensity data for low intensities and low magnitudes during the period 1840-1942, and a reduced incidence of high intensities and/or high magnitude events during the period 1943-1997. Allowance clearly needs to be made for the incompleteness of the historical record. 
Table 3: Numbers of occurrences of MM intensities likely to have occurred at chosen locations, due to known events of $M_{W} \geq 5.25$ and depth $\leq 100 \mathrm{~km}$ from the period 1840 to 1997 inclusive.

\begin{tabular}{|c|c|c|c|c|c|c|c|c|c|}
\hline $\begin{array}{l}\text { Ref. } \\
\text { No. }\end{array}$ & Location & $\begin{array}{c}\text { MMI } \\
=4\end{array}$ & $\begin{array}{l}\text { MMI } \\
=5\end{array}$ & $\begin{array}{c}\text { MMI } \\
=6\end{array}$ & $\begin{array}{c}\text { MMI } \\
=7\end{array}$ & $\begin{array}{c}\text { MMI } \\
=8\end{array}$ & $\begin{array}{c}\text { MMI } \\
=9\end{array}$ & $\begin{array}{c}\text { MMI } \\
=10\end{array}$ & Sum \\
\hline 1 & Whangarei & 1 & 0 & 0 & 0 & 0 & 0 & 0 & 1 \\
\hline 2 & Auckland & 8 & 1 & 1 & 0 & 0 & 0 & 0 & 10 \\
\hline 3 & Thames & 15 & 3 & 0 & 0 & 0 & 0 & 0 & 18 \\
\hline 4 & Hamilton & 16 & 5 & 2 & 0 & 0 & 0 & 0 & 23 \\
\hline 5 & Tauranga & 26 & 5 & 1 & 0 & 0 & 0 & 0 & 32 \\
\hline 6 & Whakatane & 43 & 14 & 4 & 1 & 0 & 0 & 0 & 62 \\
\hline 7 & East Cape & 32 & 24 & 3 & 1 & 2 & 0 & 0 & 62 \\
\hline 8 & Te Kuiti & 25 & 9 & 1 & 1 & 0 & 0 & 0 & 36 \\
\hline 9 & Rotorua & 21 & 4 & 0 & 0 & 0 & 0 & 0 & 25 \\
\hline 10 & Taumarunui & 41 & 16 & 2 & 0 & 0 & 0 & 0 & 59 \\
\hline 11 & Taupo & 38 & 22 & 3 & 0 & 1 & 0 & 0 & 64 \\
\hline 12 & Gisborne & 33 & 21 & 6 & 2 & 1 & 0 & 0 & 63 \\
\hline 13 & New Plymouth & 29 & 14 & 4 & 1 & 1 & 0 & 0 & 49 \\
\hline 14 & Ohakune & 70 & 18 & 8 & 2 & 0 & 0 & 0 & 98 \\
\hline 15 & Wairoa & 48 & 26 & 5 & 1 & 2 & 0 & 0 & 82 \\
\hline 16 & Hawera & 43 & 19 & 5 & 2 & 0 & 0 & 0 & 69 \\
\hline 17 & Wanganui & 62 & 25 & 10 & 2 & 1 & 1 & 0 & 101 \\
\hline 18 & Taihape & 72 & 27 & 7 & 2 & 1 & 0 & 0 & 109 \\
\hline 19 & Napier & 51 & 27 & 6 & 3 & 1 & 0 & 1 & 89 \\
\hline 20 & Palmerston North & 71 & 25 & 6 & 7 & 1 & 0 & 0 & 110 \\
\hline 21 & Porangahau & 41 & 27 & 13 & 5 & 2 & 0 & 0 & 88 \\
\hline 22 & Masterton & 54 & 24 & 5 & 5 & 2 & 1 & 0 & 91 \\
\hline 23 & Wellington & 46 & 31 & 7 & 1 & 1 & 1 & 0 & 87 \\
\hline 24 & Takaka & 39 & 14 & 5 & 2 & 1 & 0 & 0 & 61 \\
\hline 25 & Nelson & 47 & 20 & 5 & 2 & 1 & 0 & 0 & 75 \\
\hline 26 & Blenheim & 55 & 17 & 5 & 1 & 1 & 1 & 0 & 80 \\
\hline 27 & Westport & 45 & 11 & 9 & 0 & 2 & 0 & 0 & 67 \\
\hline 28 & Greymouth & 48 & 14 & 4 & 2 & 0 & 0 & 0 & 68 \\
\hline 29 & Hanmer Springs & 42 & 11 & 11 & 1 & 1 & 0 & 0 & 66 \\
\hline 30 & Kaikoura & 44 & 15 & 6 & 1 & 0 & 0 & 0 & 66 \\
\hline 31 & Otira & 44 & 15 & 7 & 5 & 2 & 0 & 0 & 73 \\
\hline 32 & Cheviot & 40 & 9 & 9 & 0 & 2 & 0 & 0 & 60 \\
\hline 33 & Mount Cook & 25 & 10 & 2 & 0 & 0 & 0 & 0 & 37 \\
\hline 34 & Mt Somers & 31 & 15 & 1 & 0 & 0 & 0 & 0 & 47 \\
\hline 35 & Christchurch & 32 & 7 & 5 & 0 & 0 & 0 & 0 & 44 \\
\hline 36 & Fairlie & 24 & 7 & 0 & 0 & 0 & 0 & 0 & 31 \\
\hline 37 & Timaru & 16 & 9 & 0 & 0 & 0 & 0 & 0 & 25 \\
\hline 38 & Milford Sound & 30 & 11 & 9 & 1 & 0 & 0 & 0 & 51 \\
\hline 39 & Queenstown & 32 & 12 & 2 & 0 & 0 & 0 & 0 & 46 \\
\hline 40 & Omarama & 24 & 5 & 0 & 0 & 0 & 0 & 0 & 29 \\
\hline 41 & Te Anau & 29 & 17 & 2 & 1 & 0 & 0 & 0 & 49 \\
\hline 42 & Alexandra & 21 & 3 & 1 & 0 & 0 & 0 & 0 & 25 \\
\hline 43 & Oamaru & 17 & 2 & 2 & 1 & 0 & 0 & 0 & 22 \\
\hline 44 & Dunedin & 17 & 5 & 0 & 0 & 0 & 0 & 0 & 22 \\
\hline 45 & Invercargill & 25 & 5 & 1 & 0 & 0 & 0 & 0 & 31 \\
\hline 46 & Gore & 29 & 4 & 0 & 0 & 0 & 0 & 0 & 33 \\
\hline 47 & Balclutha & 15 & 2 & 0 & 0 & 0 & 0 & 0 & 17 \\
\hline \multicolumn{2}{|c|}{ Column totals } & 1657 & 627 & 185 & 53 & 26 & 4 & 1 & 2553 \\
\hline \multicolumn{2}{|c|}{ Fraction of grand total } & 0.65 & 0.25 & 0.07 & 0.02 & 0.01 & 0.002 & 0.0004 & 1.00 \\
\hline
\end{tabular}


Table 4: Numbers of occurrences of MM intensities likely to have occurred at chosen locations, due to known events of $M_{W} \geq 5.25$ and depth $70-100 \mathrm{~km}$ from the period 1840 to 1997 inclusive.

\begin{tabular}{|c|c|c|c|c|c|c|c|c|c|}
\hline $\begin{array}{l}\text { Ref. } \\
\text { No. }\end{array}$ & Location & $\begin{array}{c}\text { MMI } \\
=4\end{array}$ & $\begin{array}{c}\text { MMI } \\
=5\end{array}$ & $\begin{array}{c}\text { MMI } \\
=6\end{array}$ & $\begin{array}{c}\text { MMI } \\
=7\end{array}$ & $\begin{array}{c}\text { MMI } \\
=8\end{array}$ & $\begin{array}{c}\text { MMI } \\
=9\end{array}$ & $\begin{array}{c}\text { MMI } \\
=10\end{array}$ & Sum \\
\hline 1 & Whangarei & 0 & 0 & 0 & 0 & 0 & 0 & 0 & 0 \\
\hline 2 & Auckland & 0 & 0 & 0 & 0 & 0 & 0 & 0 & 0 \\
\hline 3 & Thames & 0 & 0 & 0 & 0 & 0 & 0 & 0 & 0 \\
\hline 4 & Hamilton & 2 & 0 & 0 & 0 & 0 & 0 & 0 & 2 \\
\hline 5 & Tauranga & 4 & 0 & 0 & 0 & 0 & 0 & 0 & 4 \\
\hline 6 & Whakatane & 4 & 5 & 1 & 0 & 0 & 0 & 0 & 10 \\
\hline 7 & East Cape & 4 & 6 & 1 & 0 & 0 & 0 & 0 & 11 \\
\hline 8 & Te Kuiti & 4 & 0 & 0 & 0 & 0 & 0 & 0 & 4 \\
\hline 9 & Rotorua & 2 & 2 & 0 & 0 & 0 & 0 & 0 & 4 \\
\hline 10 & Taumarunui & 5 & 1 & 0 & 0 & 0 & 0 & 0 & 6 \\
\hline 11 & Taupo & 9 & 5 & 0 & 0 & 0 & 0 & 0 & 14 \\
\hline 12 & Gisborne & 3 & 6 & 1 & 0 & 0 & 0 & 0 & 10 \\
\hline 13 & New Plymouth & 3 & 2 & 0 & 0 & 0 & 0 & 0 & 5 \\
\hline 14 & Ohakune & 12 & 2 & 1 & 0 & 0 & 0 & 0 & 15 \\
\hline 15 & Wairoa & 6 & 6 & 1 & 0 & 0 & 0 & 0 & 13 \\
\hline 16 & Hawera & 5 & 2 & 0 & 0 & 0 & 0 & 0 & 7 \\
\hline 17 & Wanganui & 7 & 4 & 2 & 0 & 0 & 0 & 0 & 13 \\
\hline 18 & Taihape & 7 & 5 & 1 & 0 & 0 & 0 & 0 & 13 \\
\hline 19 & Napier & 10 & 3 & 1 & 0 & 0 & 0 & 0 & 14 \\
\hline 20 & Palmerston North & 4 & 5 & 0 & 0 & 0 & 0 & 0 & 9 \\
\hline 21 & Porangahau & 4 & 3 & 1 & 0 & 0 & 0 & 0 & 8 \\
\hline 22 & Masterton & 7 & 3 & 0 & 0 & 0 & 0 & 0 & 10 \\
\hline 23 & Wellington & 5 & 5 & 0 & 0 & 0 & 0 & 0 & 10 \\
\hline 24 & Takaka & 5 & 0 & 0 & 0 & 0 & 0 & 0 & 5 \\
\hline 25 & Nelson & 2 & 4 & 0 & 0 & 0 & 0 & 0 & 6 \\
\hline 26 & Blenheim & 5 & 2 & 0 & 0 & 0 & 0 & 0 & 7 \\
\hline 27 & Westport & 4 & 0 & 0 & 0 & 0 & 0 & 0 & 4 \\
\hline 28 & Greymouth & 3 & 0 & 0 & 0 & 0 & 0 & 0 & 3 \\
\hline 29 & Hanmer Springs & 3 & 0 & 0 & 0 & 0 & 0 & 0 & 3 \\
\hline 30 & Kaikoura & 3 & 0 & 0 & 0 & 0 & 0 & 0 & 3 \\
\hline 31 & Otira & 2 & 0 & 0 & 0 & 0 & 0 & 0 & 2 \\
\hline 32 & Cheviot & 3 & 0 & 0 & 0 & 0 & 0 & 0 & 3 \\
\hline 33 & Mount Cook & 1 & 0 & 0 & 0 & 0 & 0 & 0 & 1 \\
\hline 34 & Mt Somers & 1 & 0 & 0 & 0 & 0 & 0 & 0 & 1 \\
\hline 35 & Christchurch & 3 & 0 & 0 & 0 & 0 & 0 & 0 & 3 \\
\hline 36 & Fairlie & 1 & 0 & 0 & 0 & 0 & 0 & 0 & 1 \\
\hline 37 & Timaru & 1 & 0 & 0 & 0 & 0 & 0 & 0 & 1 \\
\hline 38 & Milford Sound & 1 & 0 & 1 & 0 & 0 & 0 & 0 & 2 \\
\hline 39 & Queenstown & 1 & 1 & 0 & 0 & 0 & 0 & 0 & 2 \\
\hline 40 & Omarama & 0 & 0 & 0 & 0 & 0 & 0 & 0 & 0 \\
\hline 41 & Te Anau & 2 & 0 & 1 & 0 & 0 & 0 & 0 & 3 \\
\hline 42 & Alexandra & 1 & 0 & 0 & 0 & 0 & 0 & 0 & 1 \\
\hline 43 & Oamaru & 1 & 0 & 0 & 0 & 0 & 0 & 0 & 1 \\
\hline 44 & Dunedin & 1 & 0 & 0 & 0 & 0 & 0 & 0 & 1 \\
\hline 45 & Invercargill & 1 & 1 & 0 & 0 & 0 & 0 & 0 & 2 \\
\hline 46 & Gore & 1 & 0 & 0 & 0 & 0 & 0 & 0 & 1 \\
\hline 47 & Balclutha & 1 & 0 & 0 & 0 & 0 & 0 & 0 & 1 \\
\hline \multicolumn{2}{|c|}{ Column total } & 154 & 73 & 12 & 0 & 0 & 0 & 0 & 239 \\
\hline \multicolumn{2}{|c|}{ Fraction of $<=100 \mathrm{~km}$ total } & 0.09 & 0.12 & 0.06 & 0 & 0 & 0 & 0 & 0.09 \\
\hline
\end{tabular}

The criteria for completeness are of two kinds, relating (i) to earthquake magnitudes and (ii) to intensities. It is assumed that

- events of $\mathrm{M}_{\mathrm{W}} \geq 6.5$ are all known for the whole period of interest, i.e. from 1840 [26], and
- $\quad$ events of $\mathrm{M}_{\mathrm{W}} \geq 5.25$ are all known from 1943 [26]. As a consequence of our three-part procedure for determining intensities it follows that

- for events of $\mathrm{M}_{\mathrm{W}} \geq 6.5$, intensities of MM4 and above 
- for events of $\mathrm{M}_{\mathrm{w}} \geq 5.25$, intensities of MM4 and above

Table 5: Illustration of the incompleteness of the historical intensity data. The "ratios" are the ratios of rates of occurrence of the various intensity levels for periods (1840-1942) / (1943-1997), and the "numbers" are the numbers of locations for which the ratios are either greater than or less than 1 . A ratio less than 1 means that the rate of occurrence is smaller for the period 1840-1942 than for the period 1943-1997.

\begin{tabular}{|l|c|c|c|c|c|c|c|}
\cline { 2 - 7 } \multicolumn{1}{c|}{} & $\begin{array}{c}\text { MMI } \\
\mathbf{= 4}\end{array}$ & $\begin{array}{c}\text { MMI } \\
\mathbf{= 5}\end{array}$ & $\begin{array}{c}\text { MMI } \\
\mathbf{= 6}\end{array}$ & $\begin{array}{c}\text { MMI } \\
\mathbf{= 7}\end{array}$ & $\begin{array}{c}\text { MMI } \\
\mathbf{= 8}\end{array}$ & $\begin{array}{c}\text { MMI } \\
\mathbf{= 9}\end{array}$ & $\begin{array}{c}\text { MMI } \\
\mathbf{1 0}\end{array}$ \\
\hline $\begin{array}{l}\text { Ratio of rate of occurrence of } \\
\text { intensity for the two time periods: } \\
\text { all locations. }\end{array}$ & 0.25 & 0.52 & 0.86 & 1.49 & 6.41 & $>1$ & $>1$ \\
\hline $\begin{array}{l}\text { number of locations } \\
\text { with ratio > 1 }\end{array}$ & 1 & 7 & 17 & 16 & 17 & 4 & 1 \\
\hline $\begin{array}{l}\text { number of locations } \\
\text { with ratio < }\end{array}$ & 46 & 39 & 21 & 9 & 2 & 0 & 0 \\
\hline
\end{tabular}

\subsection{Return periods}

Return periods for various levels of shaking were derived from counts of the composite of recorded and estimated occurrences over the assumed periods of completeness, i.e. (i) the numbers of occurrences from earthquakes of $M_{W} 6.5$ and above of each intensity MM4 to MM10 are determined from the whole period 1840-1997, and (ii) the numbers of occurrences from earthquakes of $\mathrm{M}_{\mathrm{W}}$ 5.25-6.49 of each intensity are determined from the period 1943-1997. An annual rate of occurrence for the two magnitude ranges was then obtained from the count divided by the observation period for each, and the total rate of occurrence by summing the rates as appropriate. The results expressed as return periods are given in Table 6 and plotted in Figure 7.

\section{DISCUSSION}

The main numerical results of this study are summarised in Tables 3 and 6. Table 3 gives the number of instances of each intensity estimated to have occurred at each location, due to events of $M_{W} \geq 5.25$ and $h_{c} \leq 100 \mathrm{~km}$, in the period 1840 to 1997 inclusive. Table 6 gives the average return periods for given intensity exceedance levels for each location. Note that the numbers in Table 3 are a direct count of recorded and estimated occurrences from known earthquakes and so are missing many instances of shaking from events of $\mathrm{M}_{\mathrm{W}} 5.25$ to 6.49 over the period 1840 to 1942 . The return periods of Table 6 on the other hand are derived from the combination of rates from sub-catalogues that are believed to be complete within various magnitude ranges.

Tables 3 and 6 show Whangarei to have the lowest "historical" seismic hazard, its sole seismic experience being one estimated (i.e. I(calc)) occurrence of MM4 in 158 years. Auckland has the second to lowest, followed by Balclutha at the other (i.e. southern) end of the country, and then Thames and Dunedin. The next lowest placing is competed for by Rotorua, Oamaru and Gore.

Note that the need to derive the return periods using only complete portions of the felt data catalogues has resulted in some significant data casualties. Auckland's sole experience of MM6 is not reflected in the return periods (Table 6) because it was due to an $\mathrm{M}_{\mathrm{W}} 6.1$ earthquake of 1891 . Similarly Oamaru "loses" its two MM6s and one MM7 because they were from events of $\mathrm{M}_{\mathrm{W}} 5.8$ in 1876. East Cape loses one MM8 from an $\mathrm{M}_{\mathrm{W}} 6.38$ event of 1914, Taupo one MM8 from an $M_{W} 6.0$ event of 1895, and Cheviot one MM8 from an $M_{W} 6.4$ event of 1922

The hazard of Rotorua is anomalously low (Figure 7). Despite being located in the seismically active TVZ, Rotorua has a lower level of seismic hazard than localities to the east. Rotorua also makes an interesting contrast to Taupo which, despite being only $60 \mathrm{~km}$ away and in an analogous geologic environment, has a historically much higher hazard. The rate of incidence of MM5 at Taupo is about seven times higher than at Rotorua (Table 6). In addition, Rotorua, unlike Taupo, has a lower incidence of all intensities than the three nearest locations on the western side of the TVZ, i.e. Tauranga, Te Kuiti and Taumarunui. These differences between Rotorua and Taupo are explained partly by the fact that Taupo is only about $8 \mathrm{~km}$ from the nearest (i.e. southeastern) boundary of the TVZ compared with $29 \mathrm{~km}$ for Rotorua. A second factor is that the local seismicity is higher at Taupo than at Rotorua, a difference that is reflected in the hazard maps of the most recent probabilistic seismic hazard (PSH) model for New Zealand [26].

Note that in determining the above rates for Rotorua and Taupo only magnitudes of 5.25 and higher have been considered. There are numerous instances of MM5 at Rotorua and Taupo from lower magnitude earthquakes, particularly from earthquake swarms.

The data do not allow us to single out any particular location as having the highest hazard in New Zealand. Based on historical occurrences of intensities MM8 to MM10 the highest hazard location would be Masterton, closely followed by Wanganui, Napier, Wellington, and Blenheim. Based on historical occurrences of intensities MM5 to MM8 the highest hazard location would be Porangahau, closely followed by Masterton, Otira, and, Napier. 
Table 6: Estimated average return periods (in years) for Modified Mercalli intensities at 47 locations for earthquakes of $M_{W} \geq 5.25$ and depth $h_{c} \leq 100 \mathrm{~km}$ based on the observation period 1840 to 1997 inclusive. Bracketed numbers were derived by extrapolation from the lower intensity data from the same locations.

\begin{tabular}{|c|c|c|c|c|c|c|c|c|}
\hline $\begin{array}{l}\text { Ref } \\
\text { No. }\end{array}$ & Location & $\begin{array}{c}\text { MMI } \\
\geq 4\end{array}$ & $\begin{array}{c}\text { MMI } \\
\geq 5\end{array}$ & $\begin{array}{c}\text { MMI } \\
\geq 6\end{array}$ & $\begin{array}{c}\text { MMI } \\
\geq 7\end{array}$ & $\begin{array}{c}\text { MMI } \\
\geq 8\end{array}$ & $\begin{array}{c}\text { MMI } \\
\geq 9\end{array}$ & $\begin{array}{c}\text { MMI } \\
\geq 10\end{array}$ \\
\hline 1 & Whangarei & 158 & - & - & - & - & - & - \\
\hline 2 & Auckland & 12 & 158 & - & - & - & - & - \\
\hline 3 & Thames & 5.6 & 41 & - & - & - & - & - \\
\hline 4 & Hamilton & 5.7 & 18 & (60) 55 & - & - & - & - \\
\hline 5 & Tauranga & 3.2 & 15 & (70) 158 & - & - & - & - \\
\hline 6 & Whakatane & 1.3 & 6.1 & 18 & (70) 158 & - & - & - \\
\hline 7 & East Cape & 1.3 & 2.9 & 27 & 79 & (360) 158 & - & - \\
\hline 8 & Te Kuiti & 3.1 & 12 & 28 & (90) 55 & - & - & - \\
\hline 9 & Rotorua & 3.3 & 32 & - & - & - & - & - \\
\hline 10 & Taumarunui & 1.6 & 5.8 & 79 & - & - & - & - \\
\hline 11 & Taupo & 1.5 & 4.5 & 23 & - & - & - & - \\
\hline 12 & Gisborne & 1.4 & 3.2 & 15 & 79 & (260) 158 & - & - \\
\hline 13 & New Plymouth & 1.9 & 6.2 & 20 & 79 & (260) 158 & - & - \\
\hline 14 & Ohakune & 0.9 & 4.1 & 9.0 & 79 & - & - & - \\
\hline 15 & Wairoa & 1.1 & 3.3 & 20 & 32 & 79 & - & - \\
\hline 16 & Hawera & 1.2 & 4.6 & 23 & 79 & - & - & - \\
\hline 17 & Wanganui & 0.9 & 3.0 & 9.0 & 40 & 79 & (300) 158 & - \\
\hline 18 & Taihape & 0.8 & 3.3 & 15 & 53 & (230) 158 & - & - \\
\hline 19 & Napier & 1.0 & 3.3 & 14 & 23 & 79 & (230) 158 & (670) 158 \\
\hline 20 & Palmerston North & 0.8 & 3.5 & 12 & 20 & (80) 158 & - & - \\
\hline 21 & Porangahau & 1.0 & 2.0 & 5.6 & 20 & 79 & - & - \\
\hline 22 & Masterton & 1.0 & 3.9 & 14 & 23 & 53 & (170) 158 & - \\
\hline 23 & Wellington & 1.1 & 2.6 & 12 & 53 & 79 & (340) 158 & - \\
\hline 24 & Takaka & 1.6 & 6.5 & 26 & 53 & (210) 158 & - & - \\
\hline 25 & Nelson & 1.2 & 4.6 & 18 & 53 & (200) 158 & - & - \\
\hline 26 & Blenheim & 1.2 & 5.2 & 15 & 53 & 79 & (330) 158 & - \\
\hline 27 & Westport & 1.2 & 4.1 & 8.6 & 79 & 79 & - & - \\
\hline 28 & Greymouth & 1.2 & 4.4 & 23 & 79 & - & - & - \\
\hline 29 & Hanmer Springs & 1.3 & 3.5 & 6.8 & 41 & (100) 158 & - & - \\
\hline 30 & Kaikoura & 1.4 & 3.9 & 20 & (70) 158 & - & - & - \\
\hline 31 & Otira & 1.1 & 2.6 & 6.3 & 13 & 79 & - & - \\
\hline 32 & Cheviot & 1.4 & 4.1 & 9.6 & (30) 158 & (70) 158 & - & - \\
\hline 33 & Mount Cook & 2.0 & 6.3 & 28 & - & - & - & - \\
\hline 34 & Mt Somers & 1.6 & 6.5 & (30) 55 & - & - & - & - \\
\hline 35 & Christchurch & 2.0 & 12 & 32 & - & - & - & - \\
\hline 36 & Fairlie & 2.6 & 15 & - & - & - & - & - \\
\hline 37 & Timaru & 4.9 & 16 & - & - & - & - & - \\
\hline 38 & Milford Sound & 1.4 & 3.4 & 7.8 & (20) 158 & - & - & - \\
\hline 39 & Queenstown & 1.6 & 4.8 & 41 & - & - & - & - \\
\hline 40 & Omarama & 2.8 & 13 & - & - & - & - & - \\
\hline 41 & Te Anau & 1.4 & 3.5 & 23 & (80) 158 & - & - & - \\
\hline 42 & Alexandra & 3.1 & 20 & 158 & - & - & - & - \\
\hline 43 & Oamaru & 4.9 & 41 & - & - & - & - & - \\
\hline 44 & Dunedin & 4.2 & 41 & - & - & - & - & - \\
\hline 45 & Invercargill & 2.6 & 18 & 158 (130) & - & - & - & - \\
\hline 46 & Gore & 2.3 & 20 & - & - & - & - & - \\
\hline 47 & Balclutha & 4.8 & 79 & - & - & - & - & - \\
\hline
\end{tabular}


(a) $M M I \geq 4$<smiles>C1CC2CCC(C1)N2</smiles>

\section{1}

8

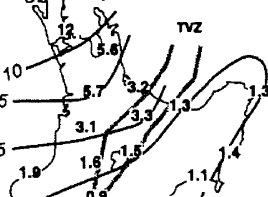

?

$$
\text { ? }
$$

(b) $M M I \geq 5$
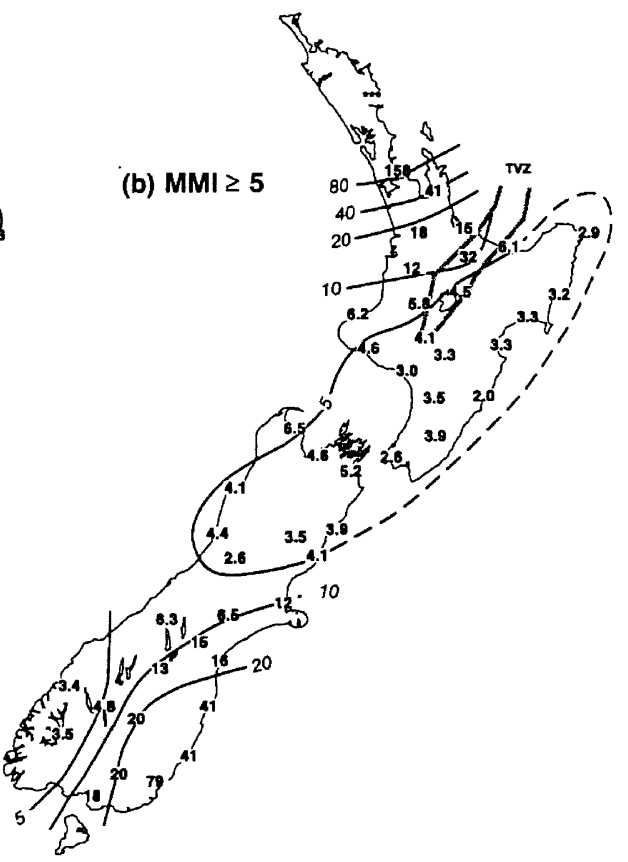

(c) $M M I \geq 6$
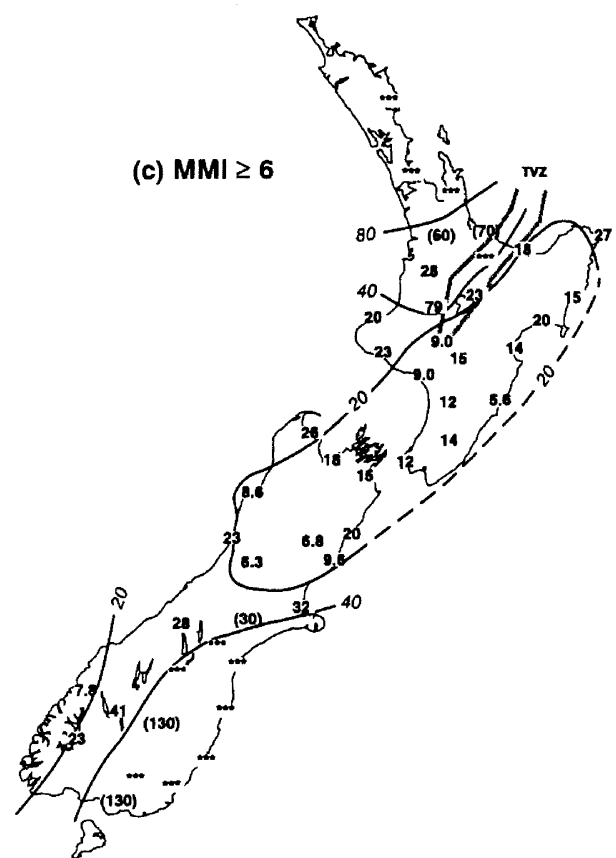

(d) $\mathrm{MMI} \geq 7$

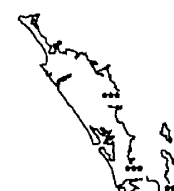

150

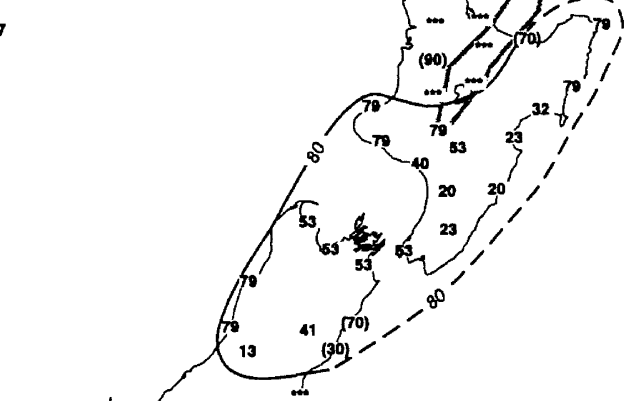

Figure 7: Map showing average return periods for historical isoseismal intensities (a) for $M M I \geq 4$, (b) for $M M I \geq 5$, (c) for $M M I \geq 6$, and (d) for $M M I \geq 7$. Values in brackets are those derived by extrapolation as replacements for the inherently unreliable "158-year" and "55-year" values, and "***" indicates that there were no observations.

Return Periods for Intensities Occurring only Once

As listed in Table 3, at about half of the locations the highest intensity has occurred only once in the 158-year study period. This leads to a nominal estimated return period of 158 years (Table 6). In view of the inherent unreliability of this return period, and the usefulness of better values, we have replaced each "158-year" return period with a value estimated by extrapolation from the other, shorter return period, results from the site concerned.

The extrapolation procedure was as follows. $\log _{10}$ (return period), excluding the "158-year" values, was plotted as a function of MMI for each location and was found to be more or less linear (Figure 8). We therefore extrapolated leastsquares fitted lines for the appropriate locations to obtain estimates of more likely return periods for those cases where the nominal return period was 158 years. The procedure was 
also followed for three cases where the highest intensity occurred once in the 55-year period from 1943 to 1997. Both the original and extrapolated values are given in Table 6 , with the (rounded) extrapolated values in brackets.

The extrapolated values of return period are longer than 158 years in half of the 24 cases. The longest extrapolated return period is 670 years, for MM10 in Napier. The sole historical occurrence of MM10 in Napier was in 1931, caused by a rupture of the Hawke's Bay fault which has an estimated average recurrence interval of 2500 years [26]. As the nearest other faults in the Napier hinterland, and the subduction interface, are likely to cause only MM8 or MM9 in Napier the extrapolated return period of 670 years is apparently pessimistic, but much more realistic than a value of 158 years.
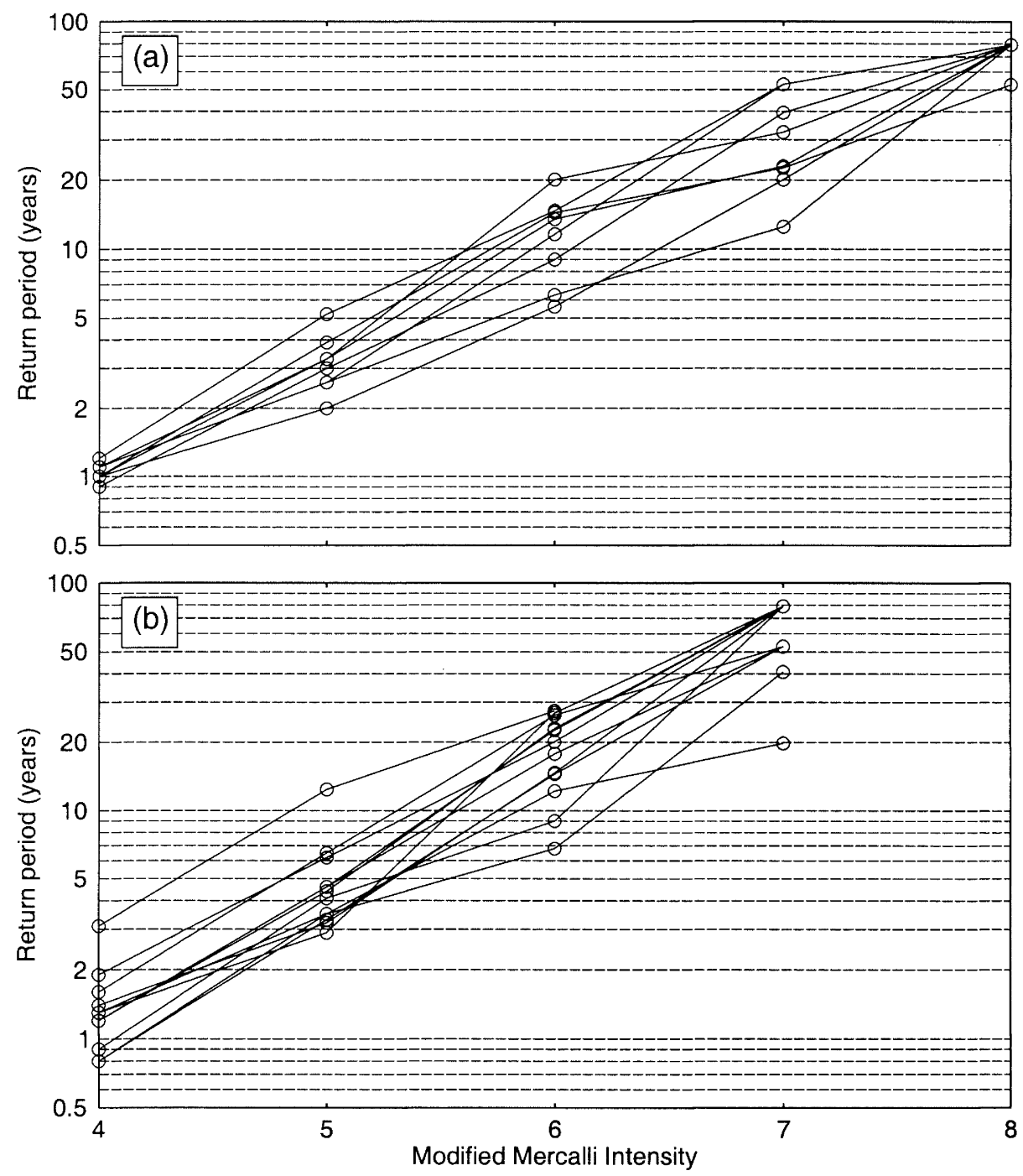

Figure 8: Return period as a function of MM Intensity for selected sites, (a) locations with 5 different return period values, and (b) locations with 4 different return period values. The logarithm of the return period appears to be a linear function of MMI for most of the observation sites.

\section{Geographical Distributions of Intensity Hazard}

In Figure 7, the return period data of Table 6 are mapped along with smoothed contour lines of constant return period. It is seen that the contour lines have similar shapes for all four intensities plotted, for example, the 1.25 year return period contour for $\mathrm{I} \geq \mathrm{MM} 4$ (Figure 7(a)) is in almost the same place as the 80 year contour for $I \geq M M 7$ on Figure 7 (d). It is of interest that the return periods of the contours in similar locations increase four-fold with each unit of intensity increase from Figure 7(a) to 7(d).
A striking feature of the maps is how clearly they demonstrate the effect of the anomalously high attenuation rate of the TVZ, with the bunching of the contours along its eastern margin, to the east of Rotorua, on Figures 7(b) and 7(c). This is important for risk assessment and for code seismic hazard zoning purposes and so we examine the geographical distribution of intensity hazard within the TVZ in more detail by considering three more locations in the TVZ in addition to Rotorua and Taupo, namely Matata, Atiamuri and Tokaanu. Taken together with Ohakune these locations cover the full $200 \mathrm{~km}$ length of the TVZ (Figure 9). For simplicity the measure of hazard used here is limited to 
the mapped isoseismal intensities, i.e. the value preferred in the rest of our study. For the full historical period we found that Atiamuri and Matata have a similar incidence of intensities to their neighbour, Rotorua, the numbers of I $\geq M M 4$ being 22,19 , and 18 respectively. In the south of the TVZ, Tokaanu is found to be intermediate to Taupo and Ohakune, with intensity counts of 33, 40 and 49 respectively for Taupo, Tokaanu and Ohakune. There is a clear increase in the occurrences from Matata in the north of the TVZ to Ohakune in the south. Finally, it is noted that the distances of the above five TVZ locations from the south-east boundary of the TVZ are approximately as follows: Matata $15 \mathrm{~km}$, Rotorua $28 \mathrm{~km}$, Atiamuri $33 \mathrm{~km}$, Taupo $8 \mathrm{~km}$ and Tokaanu $14 \mathrm{~km}$.

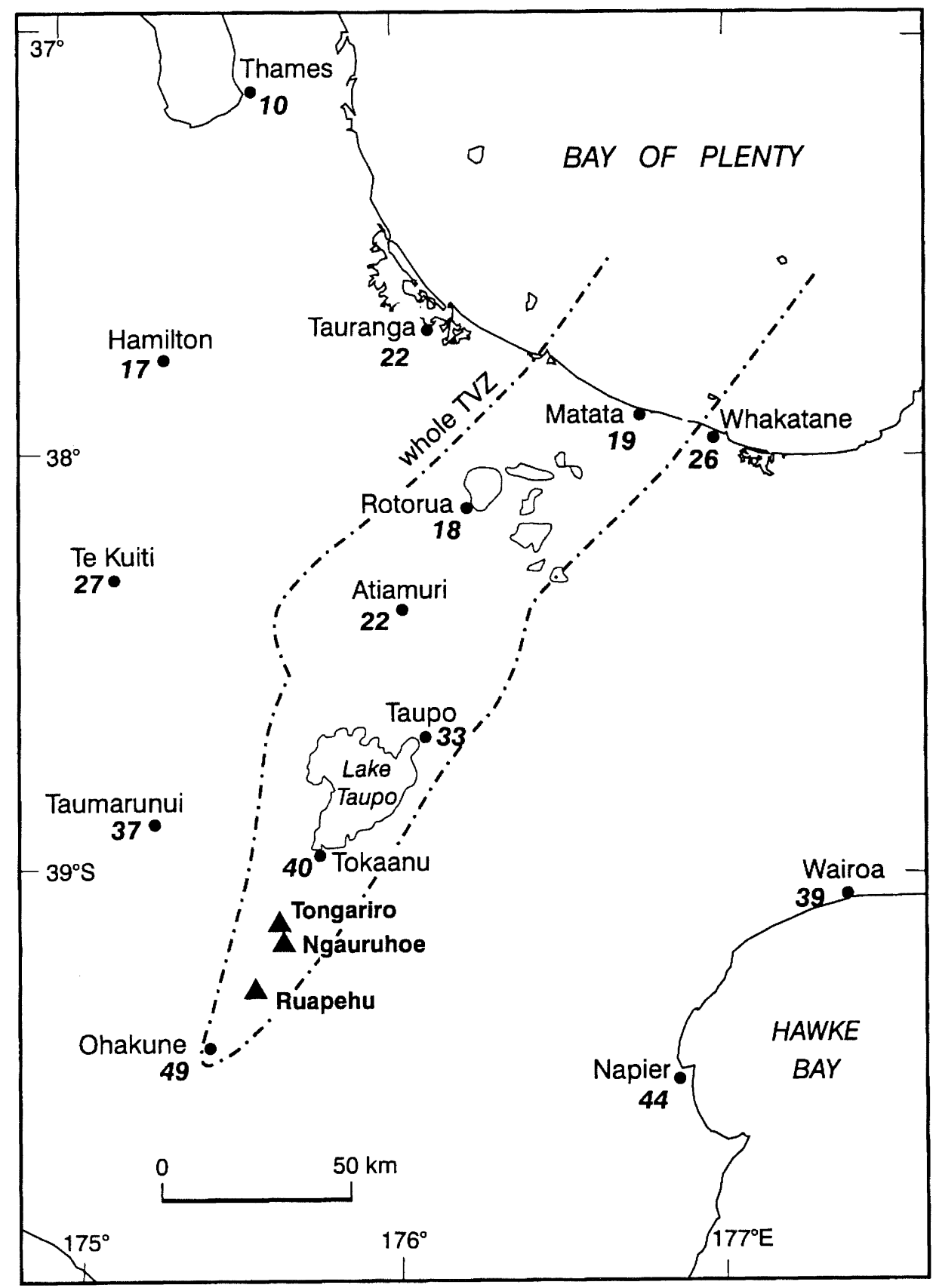

Figure 9: Map of the Taupo Volcanic Zone and hinterland showing numbers of mapped isoseismal intensities at various locations in earthquakes of $M_{W} \geq 5.25$ and $h_{c} \leq 100 \mathrm{~km}$.

\section{Contribution of Deeper Earthquakes}

The contribution to the hazard from deeper earthquakes, i.e. with depths $70-100 \mathrm{~km}$ (Figure 3), is given in Table 4. It is seen that their contribution to the total is small, with 154
MM4's, 73 MM5's and 12 MM6's. Altogether their 239 occurrences of intensity are $9 \%$ of the total of 2553 for the whole depth range $0-100 \mathrm{~km}$ considered in this study (Table 3 ). We note that earthquakes at depths greater than $70 \mathrm{~km}$ are capable of causing higher intensities than those in the 
historical record considered here. For example, the 1914 Bay of Plenty earthquake of $M_{w} 7.3$ and $h_{c} 300 \mathrm{~km}$ caused intensity MM7 over a large part of the eastern North Island [10]. In the depth range 70-100 $\mathrm{km}$ the largest event in our data set is magnitude 6.6. However, overall it appears that there is little need to extend the national seismic hazard model to include seismicity from below a depth of $100 \mathrm{~km}$.

\section{Incidence of Intensities in the North and South Islands}

Again considering the occurrences of intensities given in Table 3 , it is found that the 23 locations in the North Island experienced $56 \%$ of the 2553 intensities I $\geq$ MM4, and $65 \%$ of the 31 intensities $I \geq$ MM8. The intensities $\geq$ MM8 were caused by eight North Island earthquakes (1843, 1855, 1914(2), 1931, 1932, 1934, 1942) and seven South Island earthquakes $(1848,1901,1922,1929(2), 1968,1994)$.
Rates of Occurrence of Each Intensity

In Table 7 we summarise the annual rates of occurrence of each intensity level. In Table 7(a) the numbers are from direct counts of recorded or estimated occurrences over the two periods of interest, "pre-1943" (1840-1942, duration 103 years) and "post-1942" (1943-1997, duration 55 years). No allowance has been made for the completeness of the observations. In Table 7(b) the numbers are derived from a mix of direct count for those parts of the intensity "catalogue" that are believed to be complete, and by estimation for the incomplete part. The incomplete part of the catalogue is that for small events (i.e. $\mathrm{M}_{\mathrm{W}}<6.5$ ) over the period 1840 to 1942 . For this part of the catalogue the occurrence numbers were estimated by assuming that the occurrence rates were the same as for those post- 1942 .

Table 7: Apparent annual rates of occurrence of intensities. In (a) the numbers are from direct counts over the two periods, "pre-1943" (1840-1942, 103 years) and "post-1942" (1943-1997, 55 years). No allowances are made for the completeness of the observations. In (b) the numbers are derived from direct counts for big events $\left(M_{W} \geq\right.$ 6.5, 1840-1997), and small events $\left(M_{W}\right.$ 5.25-6.49) post-1943, whereas the numbers for small events pre-1943 are derived by scaling (i.e. by multiplying the post-1942 rates for such events by 103/55).

\begin{tabular}{|c|r|r|r|r|c|}
\hline (a) & All occurrences from direct count \\
\cline { 1 - 5 } MMI & pre-1943 & \multicolumn{1}{|c|}{$\mathbf{1 9 4 3 +}$ ("post") } & Ratio \\
\cline { 2 - 5 } & Number & $\begin{array}{c}\text { Annual } \\
\text { Rate }\end{array}$ & Number & $\begin{array}{c}\text { Annual } \\
\text { Rate }\end{array}$ & pre/post \\
\hline$=4$ & 532 & 5.17 & 1125 & 20.45 & 0.25 \\
$=5$ & 310 & 3.01 & 317 & 5.76 & 0.52 \\
$=6$ & 114 & 1.11 & 71 & 1.29 & 0.86 \\
$=7$ & 39 & 0.38 & 14 & 0.25 & 1.5 \\
$=8$ & 24 & 0.23 & 2 & 0.036 & 6.4 \\
$=9$ & 4 & 0.04 & 0 & 0.00 & - \\
$=10$ & 1 & 0.01 & 0 & 0.00 & - \\
\hline
\end{tabular}

(b) Small event $\left(M_{W}\right.$ 5.25-6.49) occurrences pre-1943 estimated, all others from direct count

\begin{tabular}{|c|r|r|r|r|c|}
\hline \multirow{2}{*}{ MMI } & \multicolumn{2}{|c|}{ pre-1943 } & \multicolumn{2}{c|}{$\mathbf{1 9 4 3 +}$ (“post") } & \multirow{2}{*}{ Ratio } \\
\cline { 2 - 5 } & Number & $\begin{array}{c}\text { Annual } \\
\text { Rate }\end{array}$ & Number & $\begin{array}{c}\text { Annual } \\
\text { Rate }\end{array}$ & pre/post \\
\hline$=4$ & 2150 & 20.87 & 1125 & 20.45 & 1.02 \\
$=5$ & 679 & 6.59 & 317 & 5.76 & 1.14 \\
$=6$ & 197 & 1.91 & 71 & 1.29 & 1.5 \\
$=7$ & 50 & 0.49 & 14 & 0.25 & 1.9 \\
$=8$ & 21 & 0.20 & 2 & 0.036 & 5.6 \\
$=9$ & 4 & 0.04 & 0 & 0.00 & - \\
$=10$ & 1 & 0.01 & 0 & 0.00 & - \\
\hline
\end{tabular}


After combining the counted and estimated parts, the rates of occurrence are virtually the same for MM4, as intended. In contrast the rate of occurrence of higher intensities ( $\mathrm{I} \geq$ MM7) is 2.5 times greater in the 103 years before 1943 than in the 55 years from 1943 to 1997 . This is a consequence of the decreased incidence of large magnitude earthquakes $\left(\mathrm{M}_{\mathrm{w}}\right.$ $\geq 7$ ) in the second half of the $20^{\text {th }}$ century in New Zealand (Table 8), and also the mostly highly "favourable" epicentral locations with respect to largely avoiding the 47 locations studied here (Figure 2). Of the four such earthquakes post1943 only one, Inangahua 1968, has given strong shaking in populated areas. The remaining three $\left(5^{\text {th }}\right.$ February $1995,1^{\text {st }}$ September 1945 and $12^{\text {th }}$ October 1979) have been well offshore or sparsely populated parts of New Zealand.

\section{Collective Rate of Occurrence of Intensities}

Considering the return periods of intensities given in Table 6 , it is interesting to note how slowly such data accumulate. It is seen that the average occurrence of $\mathrm{I} \geq \mathrm{MM} 4$ is about one per year for locations in the most seismically active parts of New Zealand while the occurrence of $I \geq$ MM5 is about one per four years. Over all of the 47 locations studied the rate of accumulation of $\mathrm{I} \geq \mathrm{MM} 4$ is about 29 per year and $\mathrm{I} \geq 5$ about 9 per year (based on Table 7(b)). Note that rates of occurrence of the lowest intensities would be significantly higher if earthquakes of $\mathrm{M}_{\mathrm{W}}<5.25$ were to also be considered.

Table 8: List of New Zealand's large $\left(M_{W} \geq 7.0\right)$ historical earthquakes. The reason for the reduced incidence of high intensities at our 47 locations from 1943 onwards is obvious. Not only has the rate of occurrence of large events been smaller from 1943 onwards (one per 14 years as against one per 7 years) but also the epicentres have mostly been particularly favourable for avoiding high intensities at the 47 locations (Figure 2). Since 1942 the Inangahua earthquake of 1968 has been the only large event onshore, and it was centred in a sparsely populated region of New Zealand.

\begin{tabular}{|c|c|c|c|c|c|c|}
\hline $\begin{array}{c}\text { Earthquake } \\
\text { Date }\end{array}$ & $\begin{array}{l}\text { Time } \\
\text { (UT) }\end{array}$ & Lat. & Long. & $\begin{array}{c}\text { Depth } \\
(\mathbf{k m})\end{array}$ & $\mathbf{M}_{\mathrm{W}}$ & Locality \\
\hline 18430708 & 0000 & 39.90 & 175.00 & 12 & 7.5 & Wanganui \\
\hline 18481015 & 1410 & 41.70 & 174.00 & 15 & 7.8 & Marlborough \\
\hline 18550123 & 0932 & 41.40 & 174.50 & 19 & 8.2 & Wairarapa \\
\hline 18630222 & 0000 & 40.00 & 176.50 & 12 & 7.5 & Southern Hawke's Bay \\
\hline 18681018 & 1235 & 40.30 & 172.67 & 10 & 7.2 & Cape Farewell \\
\hline 18880831 & 1645 & 42.60 & 172.30 & 12 & 7.2 & North Canterbury \\
\hline 19141122 & 0814 & 37.50 & 176.50 & 300 & 7.3 & Bay of Plenty \\
\hline 19290309 & 1050 & 42.80 & 171.90 & 11 & 7.0 & Arthur's Pass \\
\hline 19290616 & 2247 & 41.70 & 172.20 & 9 & 7.7 & Buller (Murchison) \\
\hline 19310202 & 2246 & 39.30 & 177.00 & 17 & 7.8 & Hawke's Bay \\
\hline 19310213 & 0127 & 39.50 & 177.50 & 17 & 7.2 & Hawke's Bay \\
\hline 19340305 & 1146 & 40.51 & 176.29 & 12 & 7.4 & Pahiatua \\
\hline 19381216 & 1721 & 45.00 & 167.00 & 47 & 7.1 & Charles Sound \\
\hline 19420624 & 1116 & 40.90 & 175.90 & 12 & 7.1 & Wairarapa I \\
\hline 19420801 & 1234 & 41.00 & 175.80 & 40 & 7.0 & Wairarapa II \\
\hline 19450901 & 2244 & 46.83 & 165.80 & 28 & 7.0 & Puysegur Bank \\
\hline 19680523 & 1724 & 41.76 & 171.96 & 10 & 7.2 & Inangahua \\
\hline 19791012 & 1025 & 46.69 & 165.74 & 12 & 7.2 & Puysegur Bank \\
\hline 19950205 & 2251 & 37.73 & 179.35 & 54 & 7.1 & Off East Cape \\
\hline
\end{tabular}

\section{COMPARISONS WITH OTHER MODELS}

First the 1992 hazard model of Smith and Berryman [23] is compared with our historical hazard record. When it was introduced about 15 years ago the Smith and Berryman model was a landmark model for New Zealand and made full use of data and interpretations then available. It is now noted that Smith and Berryman (i) did not model the high attenuation of the TVZ, (ii) adopted a relatively low magnitude cut-off of $M=4.0$, and (iii) relied on a model that was not fully probabilistic in that no allowance was made for scatter in the attenuation model.

The results of the two studies are compared in terms of the return periods for intensity $\geq M M 6$, as shown on the hazard maps of Figure 10. It is seen that the Smith and Berryman model gives generally higher estimates of the hazard than the historical record. The ratios of the historical return periods to those of Smith and Berryman at 13 locations countrywide range from 0.6 at Westport to 4.5 at Invercargill, with an average of 2.1. Thus, averaged over the country the Smith and Berryman model over-estimates the hazard, compared 
with our estimates of the historical record for I $\geq$ MM6, by a factor of two. This difference is likely to arise mainly because the attenuation model adopted for most of the country by Smith and Berryman tends to overestimate intensities. A lesser contribution to the difference comes from their lower magnitude cut-off. As well, Smith and Berryman used estimated seismicity rates near the maxima estimated from their three sub-catalogues for magnitudes 4.0 , 5.0 and 6.5 completeness.
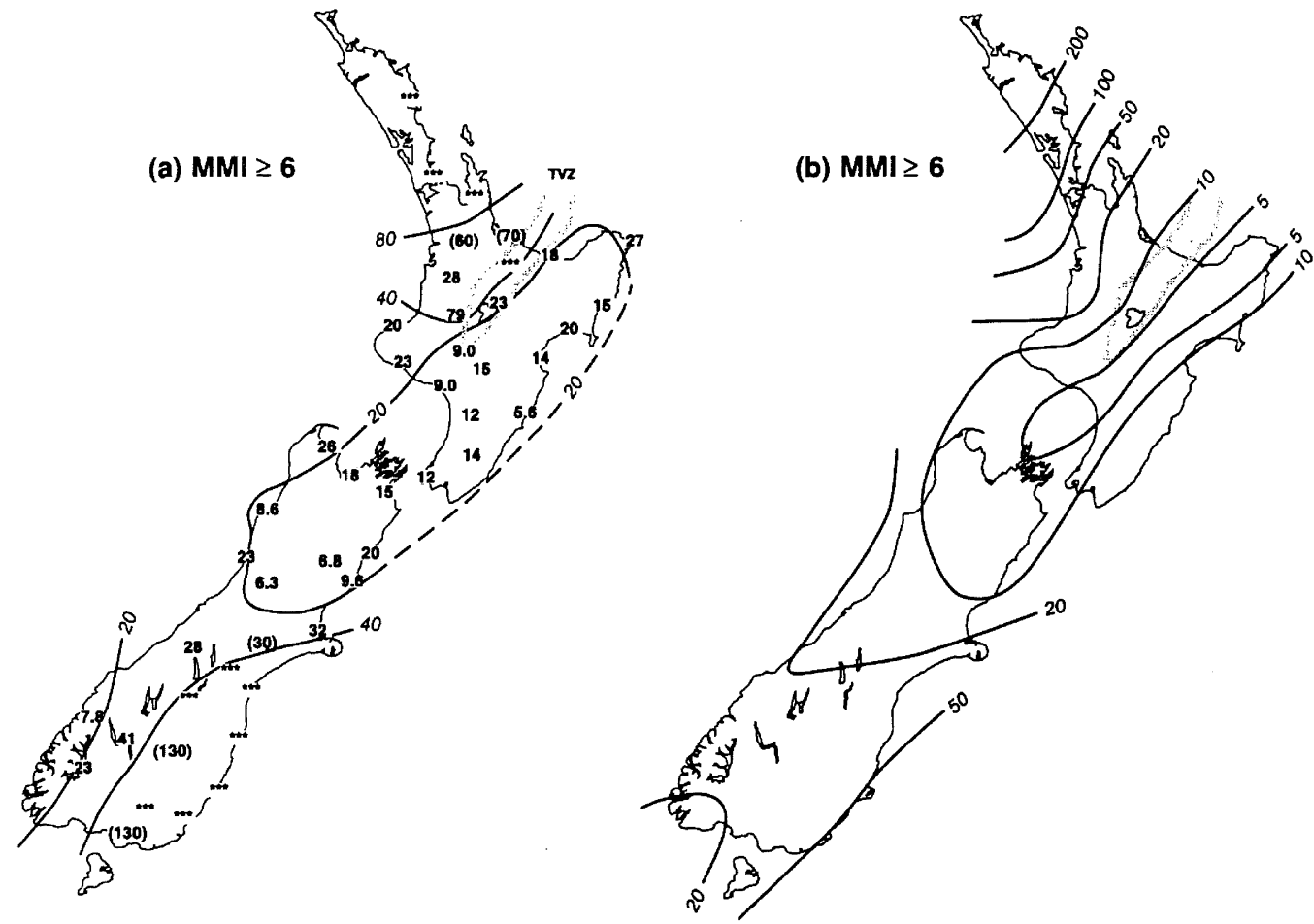

Figure 10: (a) Hazard map for I $\geq$ MM6 from historical record (this study). (b) 1999 hazard map for I $\geq$ MM6 from the 1992 semi-deterministic hazard modelling by Smith \& Berryman [23].

Next, the PSH model of Stirling et al. is compared with the estimated historical record. Because the presently published version of the PSH model [26] does not incorporate attenuation of intensity the comparison has been based on an approach that uses a synthetic catalogue of earthquakes derived from the seismicity model of the PSH model by our GNS colleague W.D.Smith. The seismicity model comprises a catalogue of 305 active faults and a model of distributed seismicity, both of which cover the entire country. For each fault there is an estimate of its mean recurrence interval of rupture and the magnitude of earthquake likely to occur on it, together with information on the likely rupture mechanism. The distributed seismicity model defines, at each of more than 40,000 points distributed over a three-dimensional, New Zealand-wide grid, the rate of occurrence of earthquakes of various magnitudes, and the maximum magnitude that can occur there.

The seismicity model was used to generate a 100,000 -year long synthetic catalogue of earthquakes for New Zealand, as follows (W.D.Smith, personal communication). For each of the active faults, a random number was generated for each year of the synthetic catalogue, and together with the mean recurrence interval was used to determine whether or not the fault would rupture in that year. For example, if the return period for a given fault was 1000 years, then there would be about 100 events on that fault in a 100,000-year catalogue. If a fault was found to rupture, a second random number was used to determine the precise magnitude of the earthquake in accordance with the characteristic magnitude value for the fault and the uncertainty in the characteristic value. The distributed seismicity was treated in a similar way: a random number determined whether or not there would be an event at that grid point in a particular year, based on the mean rate there. If indeed one did occur at that grid point in a given year, a second random number was then used to determine its magnitude.

The 100,000-year catalogue contained approximately 640,000 earthquakes with $\mathrm{M}_{\mathrm{W}} \geq 5.25$ and depth $\leq 100 \mathrm{~km}$. For each earthquake we estimated the intensities at all of our study locations using the intensity attenuation model of Dowrick \& Rhoades [10] in the same way as was done for deriving I(calc) values above. Also incorporated were the $a d$ hoc adjustments described above to account for (i) the high attenuation in the TVZ and (ii) indirect paths for events in the dipping tectonic slab $70 \mathrm{~km}$ or more beneath the western North Island.

Exceedances of various levels of MMI were then counted in 55-year blocks, about 1800 for the full 100,000-year span of the catalogue. For each location the mean counts, the standard deviations, and the maximum and minimum counts were computed. The results are compared with the "historical" occurrences of intensity MM5 and MM6 over a 55-year period (Figures 11 and 12). The "historical" 
occurrences were calculated using the return periods of Table 6. In both figures the hazard at each of the 47 locations is plotted in descending order of historical hazard. For the synthetic catalogue results we plot the means of the counts, the $95 \%$ tolerance interval (i.e. within \pm 2 standard deviations of the mean) and the ranges.

Figures 11 and 12 show that the numbers of exceedances given by the PSH model exceeds the historical record at most locations. From Figure 11 it is seen that 41 of the 47 historical MM5 data points are smaller than the values of the PSH model, with 3 being significantly so. If there was no bias between the two sets of values then the $95 \%$ tolerance interval for the number of historical data points smaller than the PSH model would be approximately 16 to 30 . Thus 41 out of 47 is a significant bias. Similarly from Figure 12 it is seen that 27 of the 47 MM6 data points are smaller than the values of the model, but with none being significantly so. If there was no bias between the two sets of MM6 values then, given that the two sets of values are equal for 12 locations, the $95 \%$ tolerance interval for the number of historical data points smaller than the PSH model would be approximately 12 to 23 . Once again the observed number, 27 , is outside the 95\% tolerance interval and so the bias is significant (D. Rhoades, pers. comm 2001). Note, however, that in this statistical test we have assumed (i) that the number of exceedances is independent between locations and (ii) that in the seismicity modelling earthquakes follow a Poisson process with time-invariant rates. Neither assumption is strictly true. We also cannot determine whether the differences are due to the seismicity model, the generation of the synthetic catalogue, to the attenuation model, or to lack of completeness in the historical record.

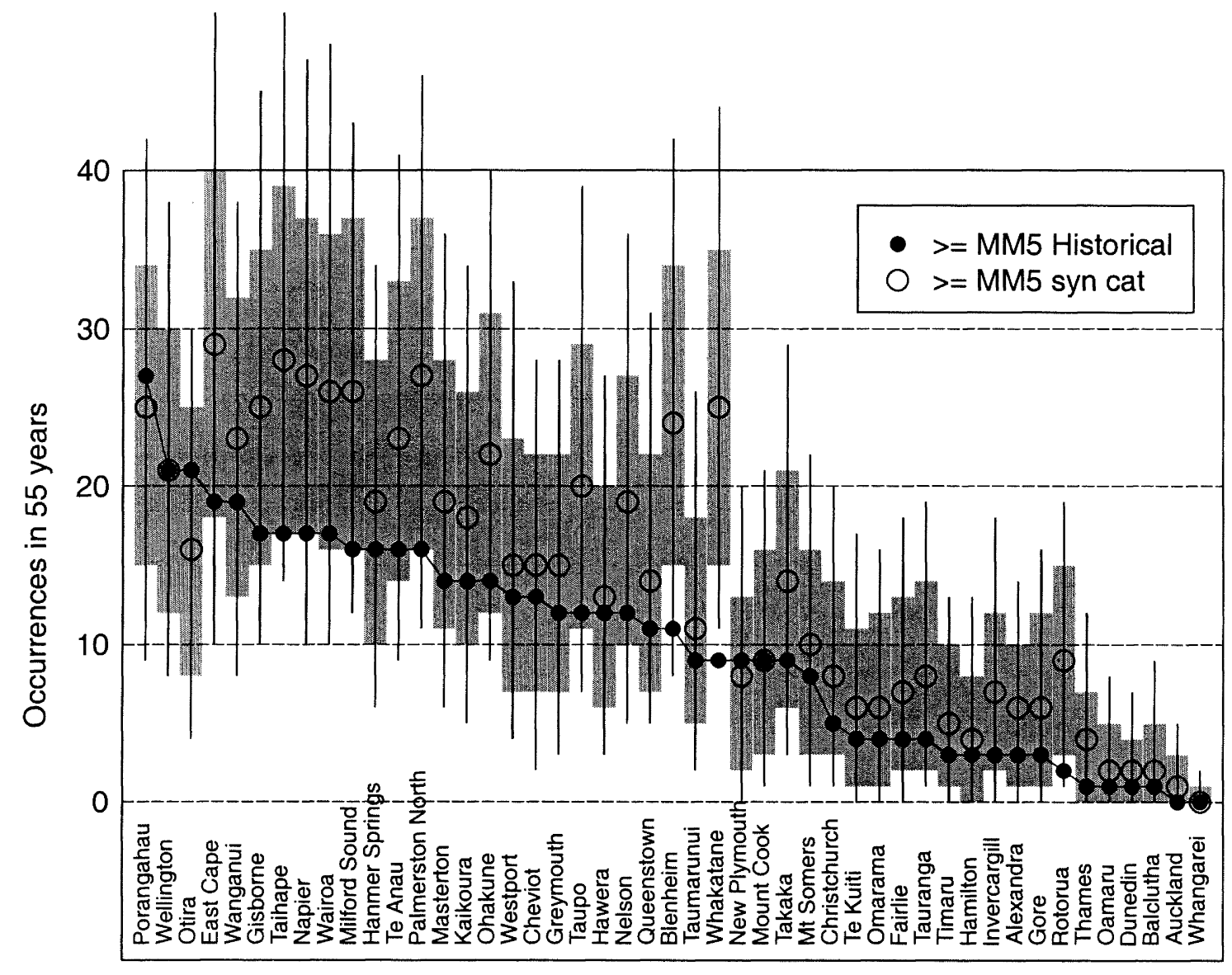

Figure 11: Expected historical occurrences of intensity $\geq M M 5$ for a 55-year period, plotted in descending order of frequency at 47 locations, compared with numbers of occurrences estimated using a 100,000-year long synthetic earthquake catalogue derived from the probabilistic seismic hazard model of Stirling et al. [26]. In the synthetic catalogue method occurrences of intensity $\geq$ MM5 were counted in 55-year blocks of earthquakes, for a total of approximately 1800 blocks. There was considerable variability from one count to another. The open circles show the means of the 1800 counts for each site, the wide bars the 95\% confidence limits, and the narrow bars the ranges. There is clearly a bias between the historical and model results, but at most sites the historical results are within the $95 \%$ confidence intervals of the model results. 


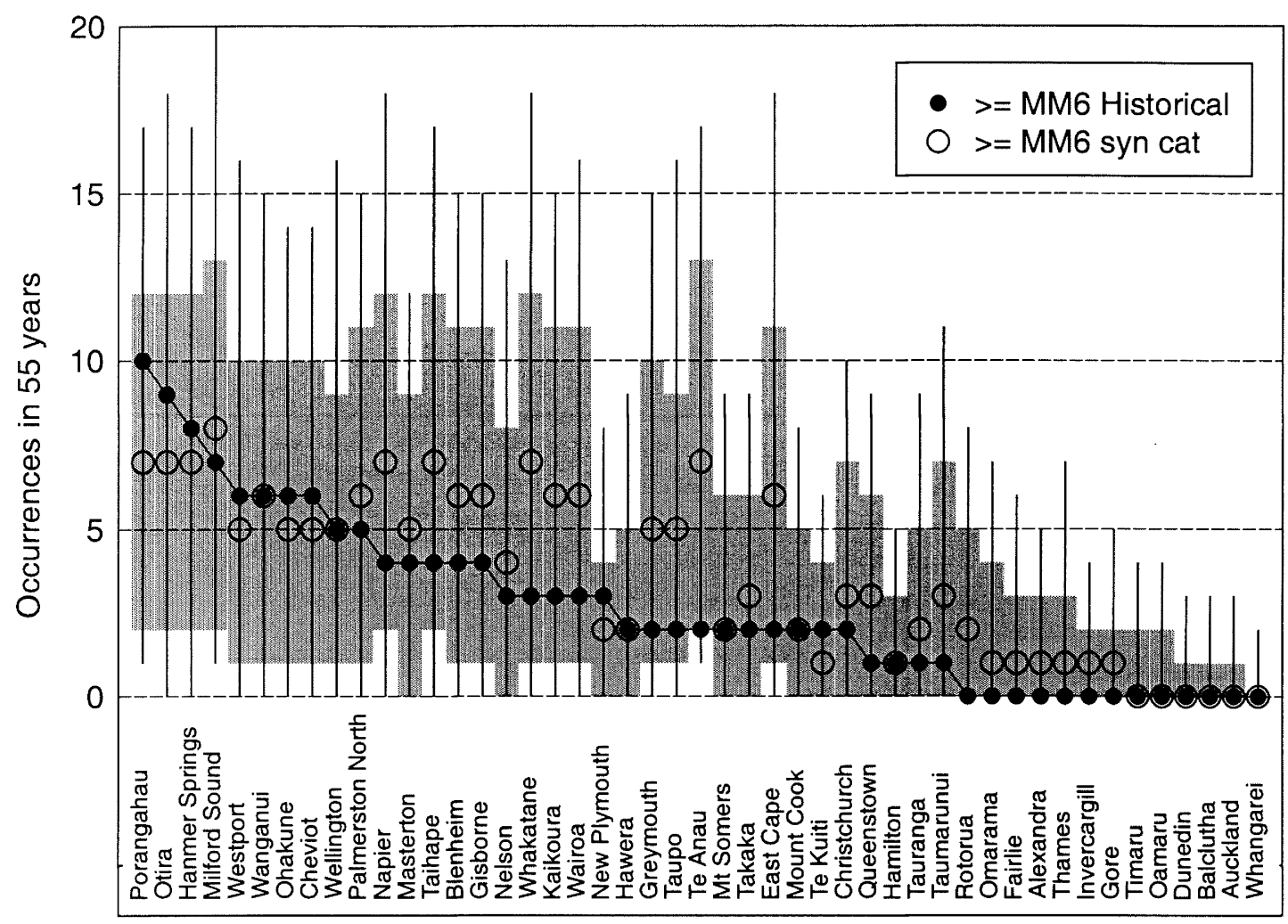

Figure 12: Expected historical occurrences of intensity $\geq M M 6$ for a 55-year period, plotted in descending order of frequency at 47 locations, compared with numbers of occurrences estimated using a 100,000-year long synthetic earthquake catalogue derived from the probabilistic seismic hazard model of Stirling et al. [26]. The open circles show the means of the 1800 counts for each site, the wide bars the 95\% confidence limits, and the narrow bars the ranges. As for Figure 10 there is clearly a bias between the historical and model results, but the differences are less than for the $\geq$ MM5 case and at most sites the historical results are in within one standard deviation of the means of the model results.

The ratio of the mean number of occurrences of MMI $\geq 5$ from the PSH method to the historical result ranges from 0.8 to 5. Importantly, however, throughout the high-hazard part of the country the PSH model value is usually within $50 \%$ of the historical value. The large ratios tend to occur either at locations affected by the TVZ or in low-hazard parts of the country, i.e. the north western part of the North Island and the south-eastern part of the South Island (Figure 13). In both cases the numbers of occurrences are usually low, sometimes zero.

In some circumstances the performance of the model as a whole (across the country) is of more interest than for the individual locations. If it is assumed that our 47 locations are a good representation of all of New Zealand then summing across all the data of Figures 11 and 12 indicates that the PSH model hazard is greater than the historical record by factors of 1.4 for both MM5 and MM6. The total numbers of occurrences of I $\geq$ MM5 over the 55-year observation period are 672 and 472 respectively for the PSH model and the historical data, and for I $\geq$ MM6 are 173 and 126.

The results were quite sensitive to some aspects of the attenuation model used in conjunction with the synthetic catalogue. For events with unknown mechanism we applied the "main seismic region" model of Dowrick \& Rhoades [10]. This separates events into two classes, "crustal" and "slab", with the boundary between the two being the upper surface of the subducting slab [eg 20]. We found it important to take account of the slab because treating all events shallower than $70 \mathrm{~km}$ as "crustal" resulted in very high occurrence rates for MMI $\geq 5$ and $\geq 6$ at eastern North Island sites. Similarly it was important to make allowance for the high attenuation in the TVZ and the indirect path for deep events in the western North Island. Factors that appeared to be of lesser importance were elliptical isoseismals compared with circular, and use of the "focal mechanisms" model for earthquakes with defined focal mechanisms. We have made no allowance for variability in the attenuation model. We expect that making such an allowance would increase the differences between the historical and PSH model estimates of hazard because adding variability to an attenuation model generally increases the rates of occurrence of the higher intensities proportionately more than it does those of the lower intensities. Because $74 \%$ of the historical data are derived from observed intensities and are therefore totally independent of the attenuation model, the increase in occurrences of, for example MM5, would be greater for the 
PSH model case than for the historical case and the differences in Figure 11 would be exacerbated.

One point that always has to be borne in mind is that our 55and 158-year observation periods are short compared with the 500-year-plus average recurrence intervals for surface rupture of many of the known active faults in New Zealand.
For example, two very important faults that have not ruptured in the historical period are the Alpine fault and the Wellington fault. Having said that, the highest hazard zones delineated in Figure 7 do tend to encompass most of the highly active faults identified in the PSH model [26] and are valid for the return periods relevant to this study, i.e. less than about 100 years.

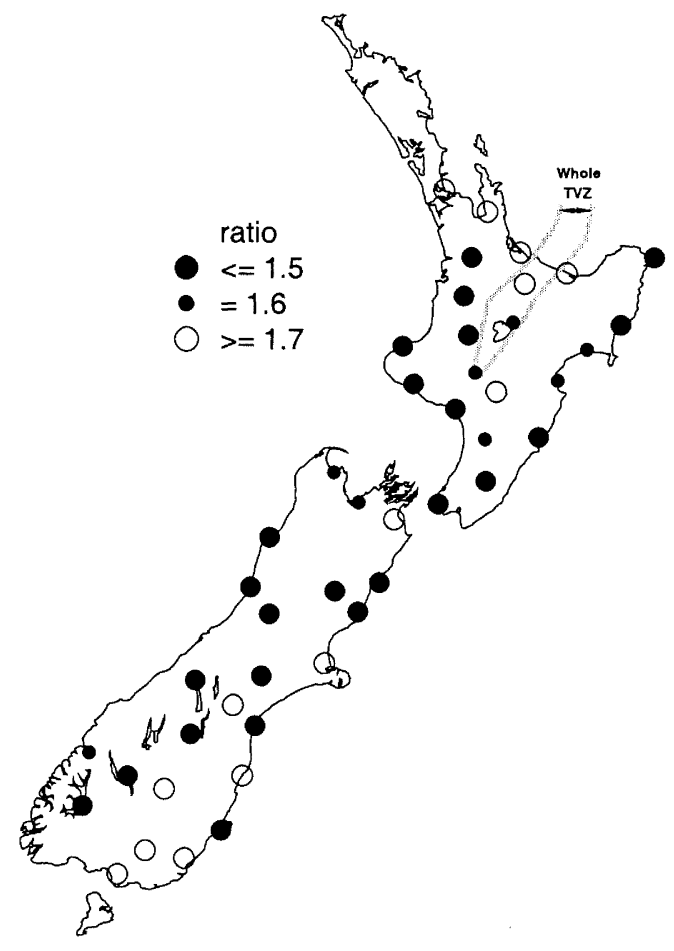

Figure 13: Comparison of historical occurrences of intensity $I \geq M M 5$ with occurrences predicted using a synthetic earthquake catalogue derived from the probabilistic seismic hazard model of Stirling et al. [26]. The ratio $P S H M / h i s t o r i c a l$ is generally $\leq 1.6$ over the highly seismic parts of New Zealand.

\section{CONCLUSIONS}

From the above study the following conclusions have been drawn:

1. The seismic hazard has been determined for 47 locations in New Zealand based on the historical incidence of Modified Mercalli intensity from 1840-1997 and for earthquakes of $\mathrm{M}_{\mathrm{W}} \geq 5.25$ and depth $\leq 100 \mathrm{~km}$.

2. The place with the lowest estimated historical seismic hazard was Whangarei, followed by Auckland, Balclutha, Thames and Dunedin. The data do not allow us to single out any particular location as having the highest hazard in New Zealand. Based on historical occurrences of intensities MM8 to MM10 the highest hazard location would be Masterton, closely followed by Wanganui, Napier, Wellington, and Blenheim. Based on historical occurrences of intensities MM5 to MM8 the highest hazard location would be Porangahau, closely followed by Masterton, Otira, and, Napier.

3. The estimated historical seismic hazard for vicinity of Rotorua, Atiamuri and Matata is anomalously low compared to surrounding locations because it is surrounded by the highly attenuating rocks of the Taupo Volcanic Zone (TVZ). The proposed loadings code for New Zealand makes partial allowance for this effect. The high attenuation within the TVZ is also evidenced by the bunching of the hazard contours (Fig. 7) within it

4. Earthquakes with depths in the range $70-100 \mathrm{~km}$ have only a small influence, restricted to lower intensities, on the total hazard. It follows that there is little need to include events deeper than $100 \mathrm{~km}$ in the national seismic hazard model.

5. On average, nine instances of $I \geq M M 5$ are recorded per year across the 47 locations studied.

6. Contours of return period were plotted for intensities 4 to 7. For many locations the return periods were found to increase 4-fold for each unit of intensity increase.

7. While the incidence of intensity $\geq$ MM4 is roughly equal in the North and South Islands, the North Island locations experienced $65 \%$ of the 31 records of $\mathrm{I} \geq$ MM8.

8. The rate of occurrence of intensities $\mathrm{I} \geq \mathrm{MM} 7$ was 
approximately 2.5 times as high in the 103 years from 1840-1942 than in the 55 years from 1943-1997. This arises from a combination of two factors, i.e. the lower incidence of large magnitude earthquakes in the recent period and the highly favourable locations of the epicentres either offshore or in remote places.

9. The seismic hazard rate modelled by Smith and Berryman [23] was found to be higher than the historical record by a factor of about 2 for I $\geq$ MM6, averaged across the country.

10. The seismic hazard estimated using a 100,000-year long synthetic catalogue of earthquakes derived from the current probabilistic seismic hazard model for New Zealand [26] was found to be higher than the historical record by a factor of about 1.4 for $\mathrm{I} \geq$ MM5 and $\geq$ MM6 over the whole country. The difference was statistically significant despite the very great variability in the numbers of occurrences of $\mathrm{I} \geq \mathrm{MM} 5$ and $\geq$ MM6 in observation periods of only 55-years duration. In general the hazard derived from the Stirling et al model [26] agrees with the historical record more closely then does the predecessor model of Smith \& Berryman.

11. Considering historical data from all of the locations, the logarithm of the return period is, on average, a linear function of the MM intensity.

12. Agreement between the historical and modelled occurrences of intensities depends very much on the detail of the attenuation model. In particular, proper allowance has to be made for events in the subducting slab and paths through the highly attenuating volcanic zone in the centre of the North Island. Both are dealt with in an ad hoc manner in the present paper.

We reiterate, that our 55- and 158-year observation periods are short compared with the 500-year-plus average recurrence intervals for surface rupture of many of the known active faults in New Zealand. The same comment applies equally to seismicity models that rely substantially on historical seismicity catalogues for New Zealand. This factor must always be borne in mind by those basing financial and design decisions on the use of such models and historical data.

\section{ACKNOWLEDGEMENTS}

This study was funded by FRST under Contract Numbers CO5804 and CO5X0006.

The authors are grateful to their colleagues Gaye Downes, Jan Harris, Diane Maunder and Brian Ferris for gathering some of the intensity data, Jiri Babor for preparing some of the data, Warwick Smith for generating a 100,000-year synthetic catalogue of New Zealand earthquakes, and David Rhoades for assessing the statistical significance of differences between historical and modelled results. Much appreciated are the efforts of Graeme McVerry, David Rhoades, Mark Stirling and Bruce Shephard for their helpful reviews of the manuscript.

\section{REFERENCES}

1. Cousins, W.J., Zhao, J.X. and Perrin, N.D. "A model for the attenuation of Peak Ground Acceleration in New Zealand based on seismograph and accelerograph data". Bulletin of New Zealand Society for Earthquake Engineering, 32(4): 193-220 (1999).

2. Downes, G.L. Atlas of Isoseismal maps of New Zealand Earthquakes. Institute of Geological \& Nuclear Sciences monograph 11, 304 p., Institute of Geological \& Nuclear Sciences, Lower Hutt, 1995.

3. Downes, G.L., Dowrick, D.J., Smith, E.G.C. and Berryman, K.R. "The 1934 Pahiatua earthquake sequence: Analysis of observational and instrumental data". Bulletin of the New Zealand Society for Earthquake Engineering, 32(4):221-245 (1999).

4. Downes, G.L., Dowrick, D.J., Van Dissen, R.J., Taber, J.J., Hancox, G.T. and Smith, E.G.C. "The 1942 Wairarapa earthquakes: analysis of observational and instrumental data. Bulletin of the New Zealand Society for Earthquake Engineering, 34(2):125-157 (2001).

5. Dowrick, D.J. "Seismic hazard estimates for the Auckland area". Bulletin of the New Zealand National Society for Earthquake Engineering, 25(3):211-221 (1992).

6. Dowrick, D. J. "Damage and intensities in the magnitude 7.8 1929 Murchison, New Zealand, Earthquake". Bulletin of the New Zealand National Society for Earthquake Engineering, 27(3): 190-204 (1994).

7. Dowrick, D.J. "The Modified Mercalli Intensity scale revisions arising from recent studies of New Zealand earthquakes". Bulletin of the New Zealand National Society for Earthquake Engineering, 29(2): 92-106 (1996).

8. Dowrick, D.J. "Damage and intensities in the magnitude 7.81931 Hawke's Bay, New Zealand, earthquake". Bulletin of the New Zealand National Society for Earthquake Engineering, 31(3): 139-163 (1998).

9. Dowrick, D.J. and Rhoades, D.A., "Magnitudes of New Zealand earthquakes, 1901-1993". Bulletin of the New Zealand Society for Earthquake Engineering, 31(4): 260280 (1998).

10. Dowrick, D.J., and Rhoades, D.A. "Attenuation of Modified Mercalli intensity in New Zealand earthquakes". Bulletin of the New Zealand Society for Earthquake Engineering, 32(2):55-89 (1999).

11. Dowrick, D.J., Berryman, K.R., McVerry, G.H. and Xhao, J.X. "Earthquake hazard in Christchurch". Bulletin of the New Zealand National Society for Earthquake Engineering, 31(1):1-23 (1998).

12. Dziewonski, A.M. et al. "Centroid moment tensor solutions". Physics of the Earth and Planetary Interiors, (various issues).

13. Eiby, G.A. "The seismicity of Auckland City and 
Northland". New Zealand Journal of Science and Technology, B(36): $488-494$ (1955).

14. Eiby, G.A. "The Modified Mercalli scale and its use in New Zealand". New Zealand Journal of Geology and Geophysics, 9:122-129 (1966).

15. Eiby, G.A. "An annotated list of New Zealand earthquakes, 1460-1965". New Zealand Journal of Geology and Geophysics, 11:630-647 (1968).

16. Hayes, R.C. "The seismicity of New Zealand cities and towns". New Zealand Journal of Science and Technology, 18: 608-612 (1936)

17. Maunder, D.E. (ed.) New Zealand seismological report 1998. Report 2000/29, Institute of Geological \& Nuclear Sciences, November 2000.

18. McGinty, P. "Preparation of the New Zealand earthquake catalogue for a probabilistic seismic hazard analysis of New Zealand". Bulletin of the New Zealand National Society for Earthquake Engineering, 34(1):60-67 (2001).

19. Reasonberg, P. "Second-order moment of central California seismicity, 1969-1982". Journal of Geophysical Research, 90:5479-5496 (1985).

20. Reyners, M. "Plate coupling and the hazard of large subduction thrust earthquakes at the Hikurangi subduction zone, New Zealand". New Zealand Journal of Geology and Geophysics, 41: 343-354 (1998)

21. Smith, E.G.C., Andrews, A.L., Davis, R.O., Dowrick,
D.J., King, A.B., Lowry, M.A. and Wood, P.R. "A revision of the Modified Mercalli seismic intensity scale, Report of a study group of the New Zealand Society for Earthquake Engineering". Bulletin of the New Zealand National Society for Earthquake Engineering, 25(4):345-357 (1992).

22. Smith, W.D. "A computer file of New Zealand earthquakes". Bulletin of New Zealand National Society for Earthquake Engineering, 9(2): 136-137 (1976).

23. Smith, W.D. and Berryman, K.R. Earthquake hazard estimates for New Zealand: effects of changes in the seismicity model. Contract Report 1992/9, Institute of Geological \& Nuclear Sciences Ltd, Lower Hutt, February 1992.

24. Smith, W.D. "A development in modelling of far-field intensities for New Zealand earthquakes". Bulletin of the New Zealand National Society for Earthquake Engineering, 28(3): 196-217 (1995).

25. Stirling, M., Yetton, M., Pettinga, J., Berryman, K. and Downes, G. Probabilistic seismic nazard assessment and earthquake scenarios for the Canterbury Region, and historic earthquakes in Christchurch. CRC Report No. U99/18, Canterbury Regional Council (1999).

26. Stirling. M., McVerry, G., Berryman, K., McGinty, P., Villamor, P., VanDissen, R., Dowrick, D., Cousins, J. and Sutherland, R. Probabilistic seismic hazard assessment of New Zealand: New active fault data, seismicity data, attenuation relationships and methods. Client Report 2000/53, Institute of Geological \& Nuclear Sciences, Lower Hutt, May 2000. 